\title{
(-)-Epicatechin Prevents Blood Pressure Increase and Reduces Locomotor Hyperactivity in Young Spontaneously Hypertensive Rats
}

\author{
M. Kluknavsky, ${ }^{1}$ P. Balis, ${ }^{1}$ A. Puzserova, ${ }^{1}$ J. Radosinska, ${ }^{2,3}$ A. Berenyiova, ${ }^{1}$ \\ M. Drobna, ${ }^{1}$ S. Lukac, ${ }^{4}{ }^{\text {J. Muchova }},{ }^{5}$ and I. Bernatova ${ }^{1}$ \\ ${ }^{1}$ Institute of Normal and Pathological Physiology, Centre of Excellence for Examination of Regulatory Role of Nitric Oxide \\ in Civilization Diseases, Slovak Academy of Sciences, Bratislava, Slovakia \\ ${ }^{2}$ Institute of Physiology, Faculty of Medicine, Comenius University, Bratislava, Slovakia \\ ${ }^{3}$ Institute for Heart Research, Slovak Academy of Sciences, Bratislava, Slovakia \\ ${ }^{4}$ Institute of Medical Physics, Biophysics, Informatics and Telemedicine, Faculty of Medicine, Comenius University, Bratislava, Slovakia \\ ${ }^{5}$ Institute of Medical Chemistry, Biochemistry and Clinical Biochemistry, Faculty of Medicine, Comenius University, \\ Bratislava, Slovakia \\ Correspondence should be addressed to I. Bernatova; iveta.bernatova@savba.sk
}

Received 30 May 2016; Revised 8 September 2016; Accepted 4 October 2016

Academic Editor: Renata Szymanska

Copyright (C) 2016 M. Kluknavsky et al. This is an open access article distributed under the Creative Commons Attribution License, which permits unrestricted use, distribution, and reproduction in any medium, provided the original work is properly cited.

\begin{abstract}
This study investigated the effects of subchronic (-)-epicatechin (Epi) treatment on locomotor activity and hypertension development in young spontaneously hypertensive rats (SHR). Epi was administered in drinking water (100 mg/kg/day) for 2 weeks. Epi significantly prevented the development of hypertension $(138 \pm 2$ versus $169 \pm 5 \mathrm{mmHg}, p<0.001)$ and reduced total distance traveled in the open-field test ( $22 \pm 2$ versus $35 \pm 4 \mathrm{~m}, p<0.01$ ). In blood, Epi significantly enhanced erythrocyte deformability, increased total antioxidant capacity, and decreased nitrotyrosine concentration. In the aorta, Epi significantly increased nitric oxide (NO) synthase (NOS) activity and elevated the NO-dependent vasorelaxation. In the left heart ventricle, Epi increased NOS activity without altering gene expressions of nNOS, iNOS, and eNOS. Moreover, Epi reduced superoxide production in the left heart ventricle and the aorta. In the brain, Epi increased nNOS gene expression (in the brainstem and cerebellum) and eNOS expression (in the cerebellum) but had no effect on overall NOS activity. In conclusion, Epi prevented the development of hypertension and reduced locomotor hyperactivity in young SHR. These effects resulted from improved cardiovascular NO bioavailability concurrently with increased erythrocyte deformability, without changes in NO production in the brain.
\end{abstract}

\section{Introduction}

Arterial hypertension is a frequent health problem worldwide. Primary hypertension is detectable in children and adolescents and is increasing in prevalence [1]. Attention deficit hyperactivity disorder (ADHD) is one of the most common developmental disorders that affects approximately $5-7 \%$ of children and adolescents [2]. The rate of learning disabilities, including ADHD, is significantly higher for children with sustained primary hypertension as compared to children without hypertension [3]. Arterial hypertension, in addition to other mechanisms, was associated with reduced deformability of erythrocytes, which may participate in the development of both arterial hypertension [4] and behavioral changes.

Spontaneously hypertensive rats (SHR) are a commonly used model of human essential hypertension. SHR also serve as an experimental model of ADHD due to their locomotor hyperactivity and reduced anxiety $[5,6]$. However, it is not clear whether the pathways involved in the development of hypertension overlap with those involved in the modulation of locomotor activity. Notably, NO serves as vasodilator in the cardiovascular system (CVS) and as neurotransmitter and neuromodulator in the central and peripheral nervous 
systems. Therefore, alterations in NO production affect both blood pressure (BP) and behavior. Indeed, neuronal nitric oxide synthase (nNOS) was shown to be involved in various behavioral abnormalities, including $\operatorname{ADHD}[7,8]$.

Oxidative stress is the excessive formation of reactive oxygen species (ROS), especially superoxide $\left(\mathrm{O}_{2}{ }^{--}\right)$, to a level exceeding the maximal capacity of the antioxidant defense mechanisms of the organism. Oxidative stress has been found to be involved in many disease states, including hypertension and behavioral/mental disorders, in both rodents and humans [9-11]. Superoxide is produced by various physiological aerobic metabolic processes as well as by several enzymatic pathways. One of the main sources of $\mathrm{O}_{2}{ }^{--}$ in living organisms is nicotinamide adenine dinucleotide phosphate oxidase (NADPH oxidase); however, uncoupled nitric oxide synthase (NOS) may also be a significant source of ROS [9]. Furthermore, increased $\mathrm{O}_{2}{ }^{--}$production may lead to formation of peroxynitrite, a strong prooxidant, which causes peroxynitrite-related cellular damage [12], observed in various cardiovascular disorders $[13,14]$.

Over the past two decades, there has been increasing interest in the potential health benefits associated with the consumption of flavanol-containing foods $[15,16]$. Several studies have reported that the consumption of flavanolcontaining foods was associated with a lower prevalence of cardiovascular diseases [17, 18]. Furthermore, several meta-analyses have confirmed a BP-lowering capacity and antihypertensive effect of flavanol-rich foods derived from cocoa $[19,20]$. BP-lowering effect of cocoa-derived products depended on the dose of ingested (-)-epicatechin (Epi) [21].

Epi is absorbed well from the gastrointestinal tract in both humans and rats, detectable in plasma approximately 30 min after ingestion. Epi concentrations peak 2-3 h after ingestion and return to baseline by $6-8 \mathrm{~h}[22,23]$, suggesting that the continuous intake of Epi-containing food is needed to maintain elevated circulation levels. The BP-reducing effect of Epi was shown in models of L-NAME-induced [24], fructose-induced [25], and DOCA-salt hypertension [26]. We have previously observed that Epi reduces $\mathrm{BP}$ and improves endothelium-dependent vasorelaxation in adult SHR with fully developed hypertension via improved vascular NO bioavailability [27].

Regarding the role of Epi in the central nervous system (CNS), recent studies have demonstrated that Epi can cross the blood-brain barrier (BBB) and enter the brain [28, 29], which may result in altered CNS function. Studies have also shown that prolonged cocoa flavanol consumption improves cognitive function, blood pressure control, and metabolic profile in elderly subjects [30]. Although the underlying mechanism responsible for the observed effects of cocoaderived foods on the CNS remains unknown, it may be associated with improved NO bioavailability, vascular function, and/or increased erythrocyte deformability, which all together may improve organ perfusion.

Therefore, the aim of this study was to investigate whether the subchronic treatment of peripubertal SHR with Epi may prevent the development of hypertension and locomotor hyperactivity in this genetic model of hypertension and ADHD. To elucidate the mechanism(s) of Epi action, we investigated superoxide and $\mathrm{NO}$ production as well as the gene expression of the $\mathrm{p} 22$ phox subunit of NADPH oxidase and individual NOS isoforms in the CVS and selected regions of the brain, total antioxidant capacity of plasma, nitrosative damage, the deformability of erythrocytes, and vascular function.

\section{Material and Methods}

2.1. Animals and Treatment. Young 5-week-old SHR males ( $n=18$ ) were used. All rats were born in our certified animal facility (Institute of Normal and Pathological Physiology SAS) in order to maintain the same environmental background for all animals. The rats were housed two per cage at constant temperature $22-24^{\circ} \mathrm{C}$ and humidity (45$60 \%$ ) with a $12: 12 \mathrm{~h}$ light-dark cycle (lights on from 06.00 a.m. to 06.00 p.m.) and fed a standard pellet diet with tap water ad libitum. At the beginning of the experiment (Basal, B), rats were randomly assigned to the control group (Cont, $n=8$ ) or a group treated with Epi (Epi, $n=10)$. Epi was administered to rats diluted in the appropriate daily volume of water, in concentration that resulted in a final daily dose of Epi approximately $100 \mathrm{mg} / \mathrm{kg}$ body weight/day, for two weeks. Daily volume of water was assessed for each cage of rats prior to starting the experiment and adjusted daily. Average daily drinking volume of rats was $17 \pm 0.8 \mathrm{~mL} / 100 \mathrm{~g}$ of body weight and Epi did not influence it. Concentrated Epi solution $(100 \mathrm{mg} / \mathrm{mL})$ was prepared fresh every day before administration to rats by dilution of Epi in tap water $\left(85^{\circ} \mathrm{C}\right.$, $3 \mathrm{~min}$, in water bath). Calculated volume of concentrated Epi solution was added to assessed volume of fresh tap water in the bottles of rats to reach the dose $100 \mathrm{mg} / \mathrm{kg}$ body weight/day after drinking out all liquid during $24 \mathrm{~h}$ period. Concentration of Epi in bottles was approximately $0.58 \mathrm{mg} / \mathrm{mL}$. If rats drank the given volume of liquid earlier, fresh water was added to the bottle to prevent thirst and/or stress from the lack of water. Epi solutions (both concentrated and diluted in bottles) were protected against the light. Fresh Epi was administered to rats at the end of the light period, as the majority of drinking activity of rodents occurs in the dark (active) period [31]; thus approximately $80 \%$ of solution was drunk during the dark period and the rest in the light period. Thermal and time-dependent stability of Epi in water has been shown previously [32].

At the end of the 2-week treatment, the rats were exposed to brief $\mathrm{CO}_{2}$ anesthesia. Rats were subsequently killed by decapitation, and trunk blood was collected to evaluate erythrocyte deformability, nitrotyrosine concentration, and total antioxidant capacity. Wet mass of the left heart ventricle (LHV) was determined to calculate relative weight (LHV/body weight) in order to ascertain the degree of LHV hypertrophy.

All procedures were performed in accordance with the institutional guidelines and approved by the Department of Animal Wellness, State Veterinary and Food Administration of the Slovak Republic.

2.2. Blood Pressure and Heart Rate. Systolic blood pressure and heart rate $(\mathrm{HR})$ were measured in preconditioned, conscious rats 
by noninvasive tail-cuff plethysmography between 08:00 a.m. and 11:00 a.m. as described in detail previously [33]. Each value was calculated as the average of five measurements. $\mathrm{BP}$ values were measured repeatedly at the beginning of the experiment (B) and after the seventh, tenth, and fourteenth day of treatment. Body weight (BW) was determined on the same days.

2.3. Open-Field Test. Rat motor activity and anxiety level were measured using the open-field test (OF) between 07:30 a.m. and 10:00 a.m. The open-field apparatus comprised a $100 \times 100 \mathrm{~cm}$ area with a black floor and black walls $(50 \mathrm{~cm}$ high) with a virtual central zone $(55 \times 55 \mathrm{~cm})$ and corners $(12.5 \times 12.5 \mathrm{~cm})$. The $\mathrm{OF}$ was illuminated by warmwhite light at $150 \mathrm{~lx}$. Rats were placed in the centre of the OF; motor activity was recorded and evaluated by ANY-maze video-tracking software (Stoelting, USA) during $10 \mathrm{~min}$ trials. The OF area was cleaned with soapy water and dried with paper towels after each trial. The following behavioral parameters were determined: total distance traveled, total time of immobility, central zone distance traveled, and time spent in the central zone and in the corners. Average speed was calculated as the ratio of total distance traveled to time of mobility for a given rat. As anxiety markers, relative central zone distance (calculated as the percentage of central zone distance with respect to total distance traveled) and relative central zone time (calculated as the percentage of time spent in the central zone with respect to total mobility time) were determined [34].

All rats were tested one day before the beginning of the experiment to determine baseline measurements (B) in 5week-old rats. Rats were randomly assigned to the control or Epi-treated group and tested again two days before the end of the experiment ( $\sim 7$ weeks of age). Thus, OF behavior was determined one day prior to BP measurement to avoid the effect of the OF test on BP level. All cages with rats were placed into a test room with the lighting and environmental conditions described above, approximately $12 \mathrm{~h}$ before the test.

2.4. Erythrocyte Deformability, Total Antioxidant Capacity of Plasma, and Nitrotyrosine Concentration. Trunk blood samples were collected in heparinized test tubes and immediately thereafter centrifuged at $850 \times \mathrm{g}$ for $10 \mathrm{~min}$ at $4^{\circ} \mathrm{C}$ to obtain plasma and erythrocytes. Plasma was separated, aliquoted, and stored at $-80^{\circ} \mathrm{C}$ until the time of analysis.

After removing the plasma, the buffy coat and upper $20 \%$ of packed red blood cells were removed by aspiration. The remaining erythrocytes were washed three times in manufacturer-formulated Cellpack solution (diluent for Sysmex blood analyser, Sysmex F-820, Japan). The washed erythrocytes were diluted in Cellpack solution $(1: 1, \mathrm{v}: \mathrm{v})$ and adjusted to $30-40 \%$ hematocrit. The diluted suspension of erythrocytes was filtered by centrifugation through membrane filters with pores of $5 \mu \mathrm{m}$ in diameter (Ultra-freeMC SV Centrifugal Filter, Millipore, Germany) at $1400 \mathrm{rpm}$ (Hettich MIKRO 120 centrifuge). Erythrocyte deformability was calculated as the percentage of filtered erythrocytes with respect to the number of erythrocytes counted before centrifugation [35].
The total antioxidant capacity (TAC) of plasma was measured by determining the trolox equivalent antioxidant capacity as described previously by [36]. Quantification was performed using the dose-response curve for the reference antioxidant trolox, which is a water-soluble form of vitamin E. The results are presented as mmol of trolox/L. TAC was determined in six control and six Epi-treated rats.

Concentration of nitrotyrosine in plasma was detected by ELISA using commercially available kit (HK501-02, Hycult Biotech, Uden, Netherlands) according to the manufacturer's protocol. Absorbance of the plasma samples was measured at $450 \mathrm{~nm}$. The nitrotyrosine concentration of samples was determined from the standard curve and expressed in $\mathrm{nmol} / \mathrm{L}$.

2.5. Superoxide Production. The production of superoxide $\left(\mathrm{O}_{2}{ }^{--}\right)$was measured in tissue samples of the LHV and thoracic aorta $(15-20 \mathrm{mg})$ by lucigenin-enhanced chemiluminescence $(50 \mu \mathrm{mol} / \mathrm{L})$ using a TriCarb 2910TR liquid scintillation analyser (Perkin Elmer), as described previously [37]. The results are expressed as counts per minute per milligram of tissue (cpm/mg).

2.6. Nitric Oxide Synthase Activity. Total NOS activity was measured in the $20 \%$ tissue homogenates of the LHV, aorta, brainstem, and cerebellum by determining $\left[{ }^{3} \mathrm{H}\right]$-L-citrulline formation from $\left[{ }^{3} \mathrm{H}\right]$-L-arginine (MP Biomedicals, USA) as described previously [33] and expressed as $\mathrm{pmol} / \mathrm{min} / \mathrm{mg}$ of tissue proteins as determined using the Lowry method. NOS activity was determined in six control and eight Epi-treated rats.

2.7. Vascular Function. The vascular reactivity of the aorta was investigated as described previously [38]. Endotheliumdependent vasorelaxant responses were examined in rings precontracted with phenylephrine $(3 \mu \mathrm{mol} / \mathrm{L})$ to produce a stable plateau of contraction. After a contraction plateau had been reached, increasing concentrations of acetylcholine (ACh, $0.001-10 \mu \mathrm{mol} / \mathrm{L}$ ) were added cumulatively. When the ACh-induced concentration-relaxation curve was completed, the drugs were washed out $(20 \mathrm{~min})$, and the same experiment was repeated after 25 min preincubation with $\mathrm{NO}$ synthase inhibitor $\mathrm{N}^{\mathrm{G}}$-nitro-L-arginine methyl ester (LNAME, $300 \mu \mathrm{mol} / \mathrm{L})$. After this procedure and a $30 \mathrm{~min}$ washout period, the NO donor sodium nitroprusside (SNP, $0.001-10 \mu \mathrm{mol} / \mathrm{L}$ ) was added cumulatively to the $3 \mu \mathrm{mol} / \mathrm{L}$ phenylephrine precontracted aortae. The extent of vasorelaxation was expressed as the percentage change with respect to stable phenylephrine-induced contraction.

NO-independent component of endothelium-dependent ACh-induced relaxation was determined as the rest of relaxation present after inhibition of vascular NO production with L-NAME and expressed as the area under the concentrationresponse curve (AUC), in arbitrary units (a.u.). Endotheliumdependent $\mathrm{ACh}$-induced relaxation mediated by $\mathrm{NO}$ (i.e., NO-dependent component) was calculated as the difference in the AUC before L-NAME pretreatment (i.e., total AChinduced relaxation) and after L-NAME pretreatment (i.e., 
TABLE 1: Primer pairs used to amplify selected genes.

\begin{tabular}{lccl}
\hline Genes & Forward (sense) primer & Reverse (antisense) primer & Temp \\
\hline eNOS & CCC ACA GTC TGG TTG CT & TCA CCG TGC CCA TGA GT & $57^{\circ} \mathrm{C}$ \\
iNOS & TGG AGG TGC TGG AAG AGT T & GGA GGA GCT GAT GGA GTA GT & $57^{\circ} \mathrm{C}$ \\
nNOS & CGC TAC GCG GGC TAC AAG CA & GCA CGT CGA AGC GGC CTC TT & $60^{\circ} \mathrm{C}$ \\
$\beta$-actin & AAT CGT GCG TGA CAT CAA AG & ATG CCA CAG GAT TCC ATA CC & $57^{\circ} \mathrm{C}$ \\
p22phox & CAG GCA TAT ACC CGC TAC CT & TCT GTC ACC CTG TGC TTG AC & $60^{\circ} \mathrm{C}$ \\
\hline
\end{tabular}

NO-independent relaxation). AUC was calculated from individual concentration-response curves, as it was described in detail previously [33].

2.8. Gene Expression. Expression levels of neuronal NOS (nNOS), inducible NOS (iNOS), and endothelial NOS (eNOS) as well as p22phox (a transmembrane subunit of NADPH oxidase) were investigated by real-time quantitative polymerase chain reaction (RT-qPCR) using a CFX96 RealTime PCR detection system (Bio-Rad, USA). Total RNA from the brainstem, cerebellum, and LHV samples was isolated using TRIsure reagent (Bioline, United Kingdom) according to the manufacturer's protocol. The amount of total RNA isolated was quantified spectrophotometrically at 260/ $280 \mathrm{~nm}$ using a NanoDrop spectrophotometer (Thermo Scientific, USA).

For reverse transcription (Eppendorf Mastercycler, Germany), $1 \mu \mathrm{g}$ of total RNA was added to $20 \mu \mathrm{L}$ of reaction medium using a SensiFAST ${ }^{\mathrm{TM}}$ cDNA Synthesis Kit (Bioline, UK) according to the manufacturer's protocol.

The primer pair specifications used to amplify the genes studied (nNOS, iNOS, eNOS, and p22phox, resp.) as well as a housekeeping gene ( $\beta$-actin) are listed in Table 1. The PCR mixture contained $1.5 \mu \mathrm{L}$ of template cDNA diluted tenfold, $10 \mu \mathrm{L}$ SensiFAST mix (SensiFAST SYBR NoROX kit, Bioline, UK), $1.5 \mu \mathrm{L}$ of both forward and reverse primers (Metabion, Germany, $4 \mu \mathrm{mol} / \mathrm{L}$ ), and $5.5 \mu \mathrm{L}$ diethylpyrocarbonate-treated water (Sigma-Aldrich, Germany) in a final volume of $20 \mu \mathrm{L}$. The thermal cycling conditions were as follows: (1) $50^{\circ} \mathrm{C}$ for $2 \mathrm{~min}$, (2) $95^{\circ} \mathrm{C}$ for $2 \mathrm{~min}$, (3) 39 cycles consisting of (a) $95^{\circ} \mathrm{C}$ for $5 \mathrm{sec}$, (b) an optimal annealing temperature (depending on the selected primer, see Table 1) for $10 \mathrm{sec}$, and (c) $72^{\circ} \mathrm{C}$ for $5 \mathrm{sec}$ for PCR product elongation, and (4) $72^{\circ} \mathrm{C}$ for $1.5 \mathrm{~min}$. Finally, melt curves for amplicon analyses were constructed at $50-99^{\circ} \mathrm{C}, 10 \mathrm{sec} / 1^{\circ} \mathrm{C}$. Samples were measured using Bio-Rad CFX Manager software (version 2.0) and $\beta$-actin as the housekeeping gene. Gene expression was determined in six control and eight Epitreated rats and expressed as the ratio of gene expression with respect to $\beta$-actin levels.

All chemicals used in this study were purchased from Sigma-Aldrich (Germany) and Merck Chemicals (Germany), if not stated differently. Epi was purchased from Sigma (Germany, Cat. no. E1753).

2.9. Statistical Analysis. Results were analysed by unpaired Student $t$-test or one-way analysis of variance (ANOVA) where appropriate. BP, HR, and BW were analysed by twoway ANOVA (treatment $\times$ time). Vascular function was analysed by two-way ANOVA (treatment $\times$ ACh concentration). All ANOVA analyses were followed by the Bonferroni post hoc test. Values were considered to differ significantly when $p<0.05$. Data are presented as mean \pm standard error of the mean (SEM). Correlations between variables were determined using Pearson's correlation coefficient $(r)$. GraphPad Prism 5.0 (GraphPad Software, Inc., USA) and Statistica 7 (Stat Soft, Inc., USA) were used for the statistical analyses.

\section{Results}

Two-week Epi treatment had no effect on the increase in BW controlled for age (data not shown). Relative weight of the LHV was similar in the Epi $(2.21 \pm 0.07 \mathrm{mg} / \mathrm{g})$ and control $(2.31 \pm 0.06 \mathrm{mg} / \mathrm{g})$ groups. BP was reduced by approximately $18 \%$ in Epi-treated rats as compared to controls at the end of treatment (Figure 1(a)). Epi treatment reduced heart rate only on the 10th day of treatment $(571.8 \pm 17 \mathrm{bpm}$ in control versus $524.8 \pm 8.2 \mathrm{bpm}$ in Epi, $p<0.05)$ while only nonsignificant difference $(540 \pm 19 \mathrm{bpm}$ versus $530 \pm 9 \mathrm{bpm})$ was observed on day 14. In addition, Epi increased erythrocyte deformability by approximately $8 \%(p<0.05)$, increased the TAC $(p<$ $0.05)$, and reduced nitrotyrosine concentration in plasma $(p<0.05)$ versus controls (Figures 1(b), 1(c), and 1(d)).

Regarding rat behavior, repeated testing in the open-field at the end of experiment led to habituation of locomotor activity detected as reduction of total distance traveled and increase of total immobility compared to Basal values (Figures 2(a) and 2(b)). Epi administration led to a significant decrease in locomotor activity as represented by total distance traveled (Figure 2(a)), increased immobility (Figure 2(b)), and reduced the average speed of movement (Figure 2(g)) in treated animals as compared to age-matched controls. Epi decreased the distance traveled (Figure 2(c)) and time spent in the central zone (Figure 2(d)). In addition, Epi reduced both relative distance traveled and relative time spent in the central zone (Figures 2(e) and 2(f)). Epi treatment also significantly elevated time spent in the corners (Figure 2(h)) in treated animals as compared to controls.

Epi significantly reduced $\mathrm{O}_{2}{ }^{--}$production and increased NOS activity in the LHV (Figures 3(a) and 3(b)). However, Epi failed to affect gene expression levels for individual NOS isoforms (Figures 3(c)-3(e)) and p22phox (Figure 3(f)) in the LHV. 


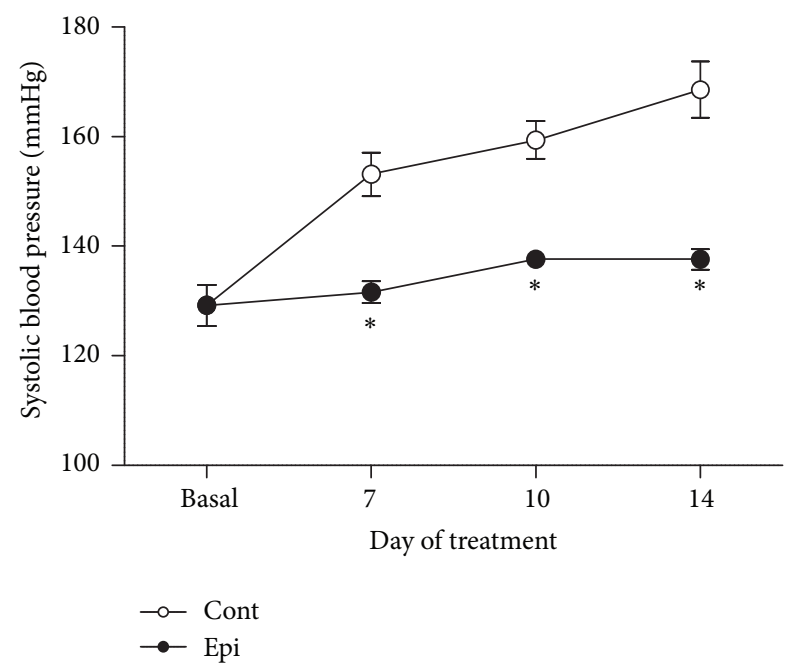

(a)

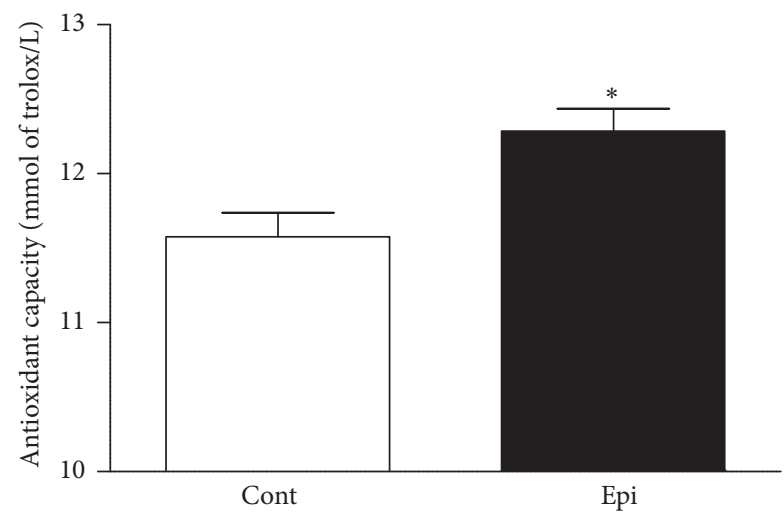

(c)

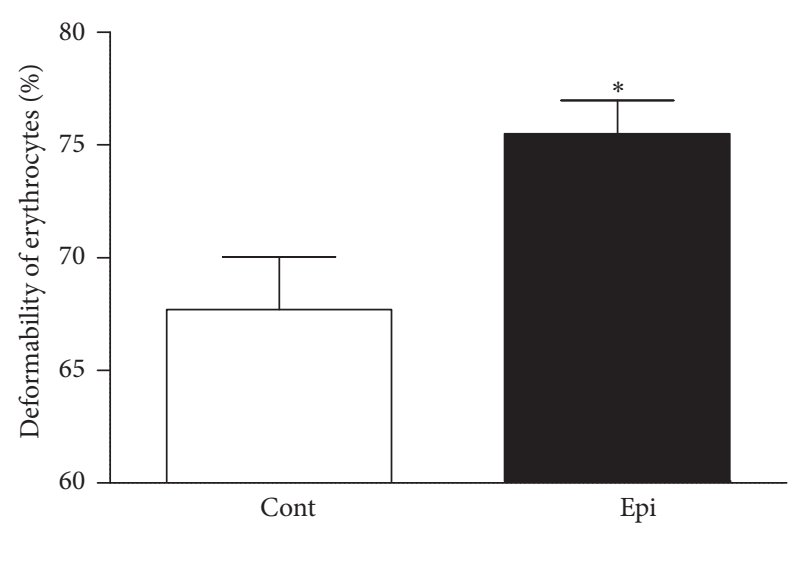

(b)

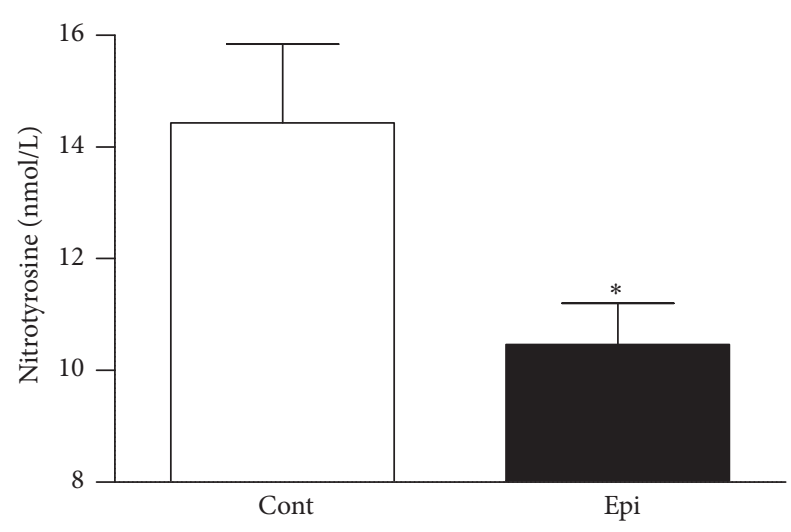

(d)

FIGURE 1: Effect of (-)-epicatechin on systolic blood pressure (a), deformability of erythrocytes (b), total antioxidant capacity of plasma (c), and plasma nitrotyrosine concentration (d) in spontaneously hypertensive rats. ${ }^{*} p<0.05$ versus Cont group. Values represent mean \pm SEM; $n=6-8$ for Cont and $n=6-10$ for Epi. Abbreviations: Cont: control group and Epi: (-)-epicatechin-treated group.

In the aorta, Epi significantly reduced $\mathrm{O}_{2}{ }^{\cdot-}$ production and increased NOS activity (Figures 4(a) and 4(b)). Neither endothelium-independent relaxation responses induced by SNP nor overall endothelium-dependent relaxation induced by ACh differed significantly in the aortae of control as compared to Epi-treated rats (Figures 4(c) and 4(d)). Acute LNAME pretreatment, which inhibited NO-dependent relaxation, inhibited relaxation more strongly in Epi-treated rats as compared to controls (Figure 4(e)). Calculation of the AUC revealed that Epi significantly increased endothelial NOdependent relaxation by approximately $26 \%$ versus control and concurrently decreased endothelial NO-independent relaxation in the aorta (Figure 4(f)).

NOS activity was unaffected by Epi in both brain regions investigated (brainstem and cerebellum) (Figures 5(a) and 6(a)). Interestingly, NOS activity in the brainstem and cerebellum correlated positively with total distance traveled (as shown in Figures 5(b) and 6(b)) as well as with central zone distance traveled in the OF $(r=0.53, p<0.05, n=14$ for brainstem; $r=0.62, p<0.02, n=14$ for cerebellum).
Gene expression levels of nNOS increased (Figures 5(c) and 6(c)) while iNOS levels remained the same in both brain regions investigated in Epi-treated rats (Figures 5(d) and 6(d)). Interestingly, eNOS and p22phox gene expression were increased in the cerebellum of Epi-treated rats as compared with controls (Figures 6(e) and 6(f)). This effect was not observed in the brainstem.

\section{Discussion}

This study investigates the effect of subchronic treatment with Epi in young SHR rats, at the peripubertal age, which is a critical developmental period when BP increases rapidly in SHR $[39,40]$. We show that continuous Epi treatment during this period significantly prevented BP increase and reduced spontaneous locomotor hyperactivity in SHR. In addition, we show here for the first time that Epi treatment increased erythrocyte deformability in SHR.

In this study, Epi was administered continuously in tap water. It is known that Epi is subject to partial degradation in 


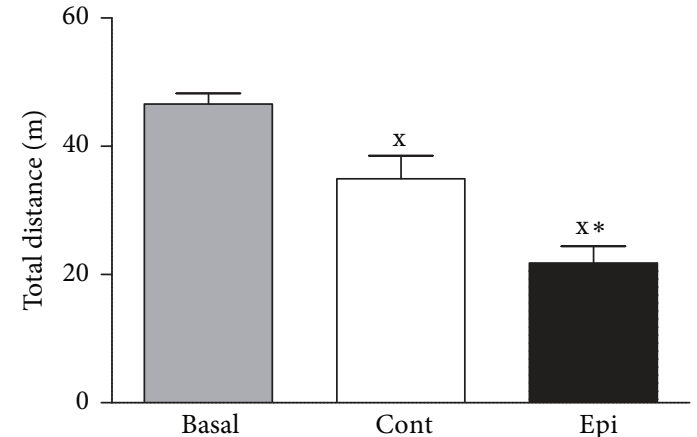

(a)

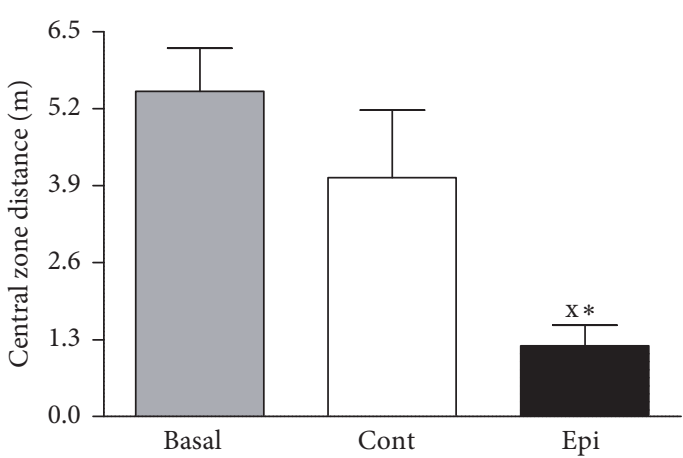

(c)

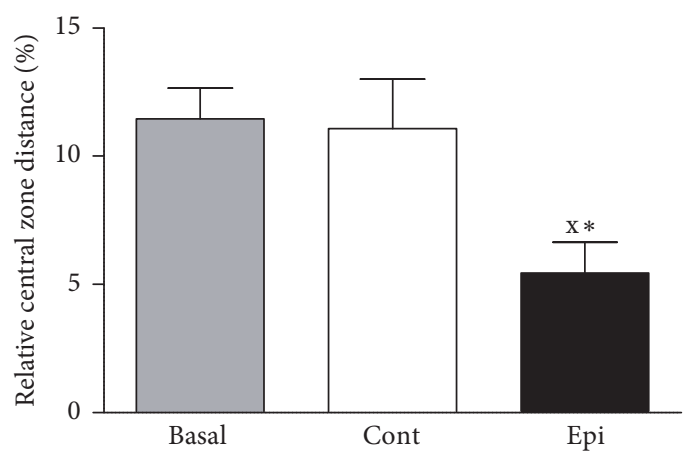

(e)

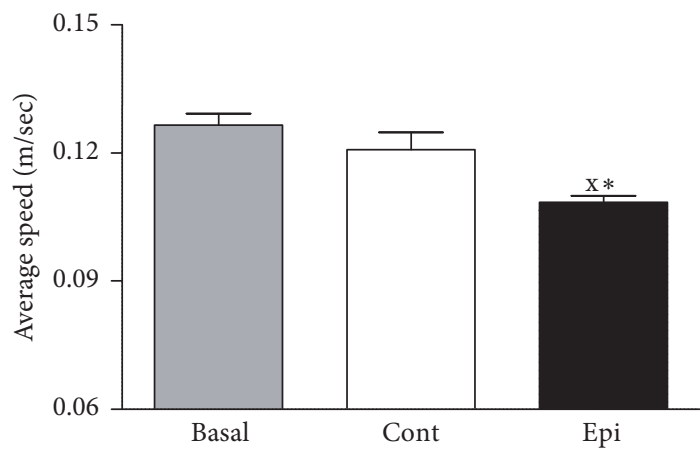

(g)

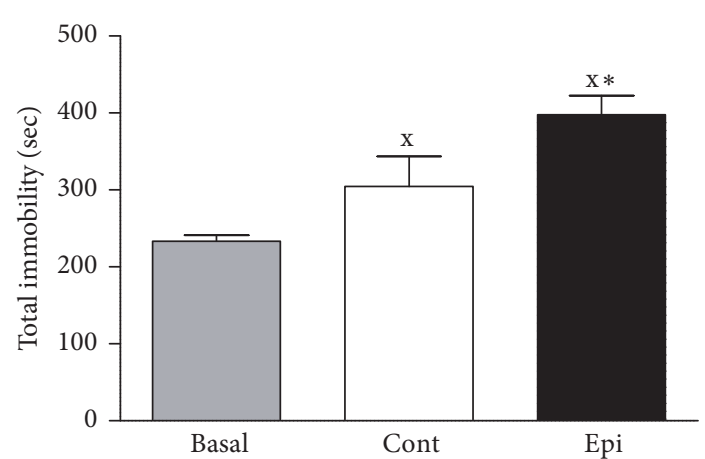

(b)

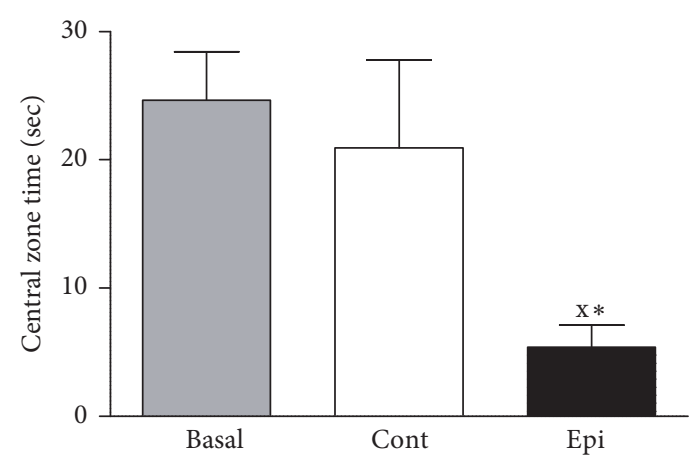

(d)

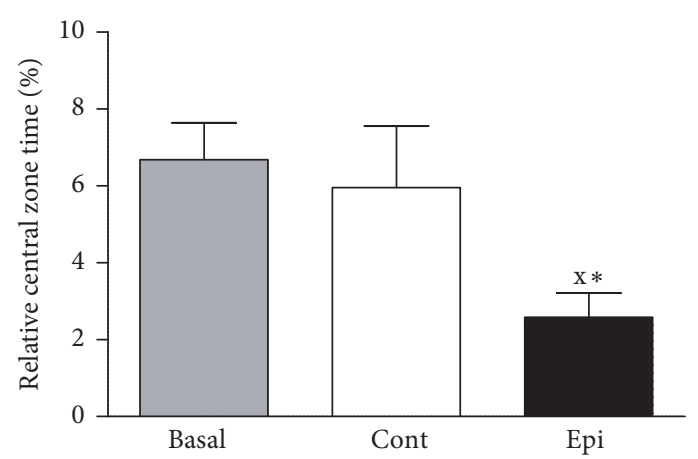

(f)

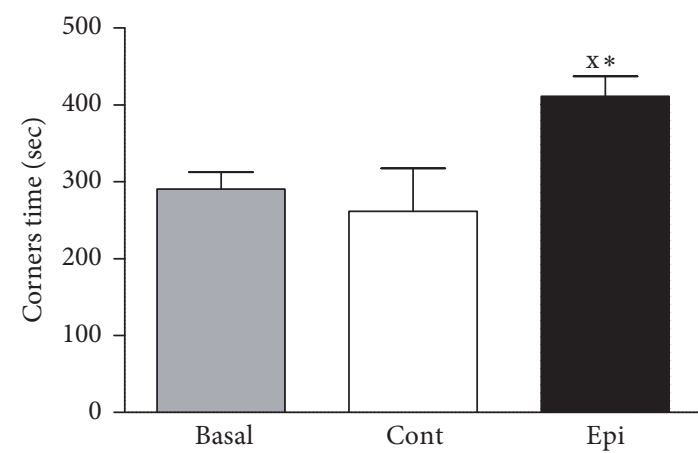

(h)

FIGURE 2: Effect of (-)-epicatechin treatment on open-field behavior of spontaneously hypertensive rats. Total distance traveled (a), total immobility (b), distance traveled in the central zone (c), time spent in the central zone (d), relative central zone distance (e), relative central zone time (f), average speed (g), and time spent in the corners (h). Values represent mean \pm SEM; $n=18$ for Basal, $n=8$ for Cont, and $n=10$ for Epi. ${ }^{\mathrm{x}} p<0.05$ versus Basal values; ${ }^{*} p<0.05$ versus Cont group. Abbreviations: Cont: control group and Epi: (-)-epicatechin-treated group. 


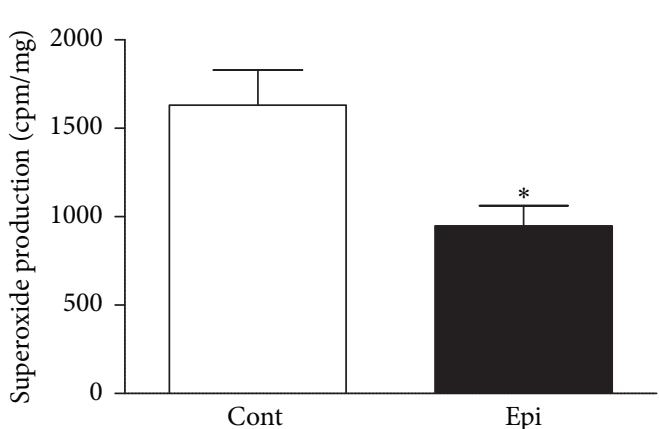

(a)

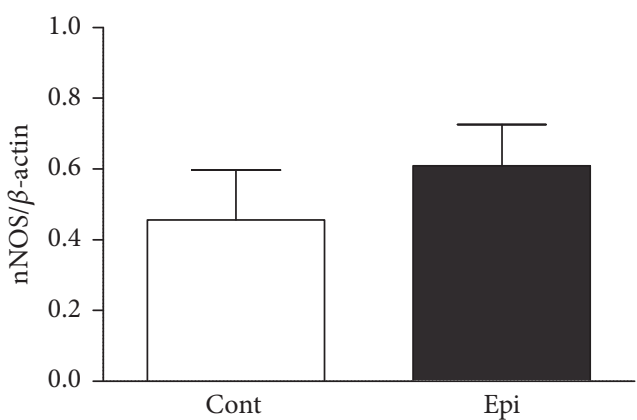

(c)

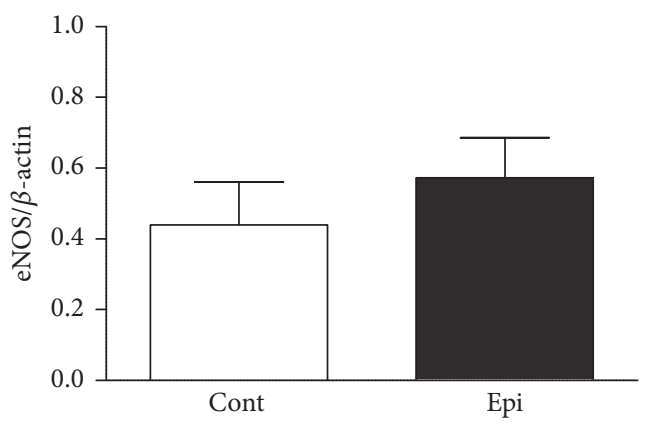

(e)

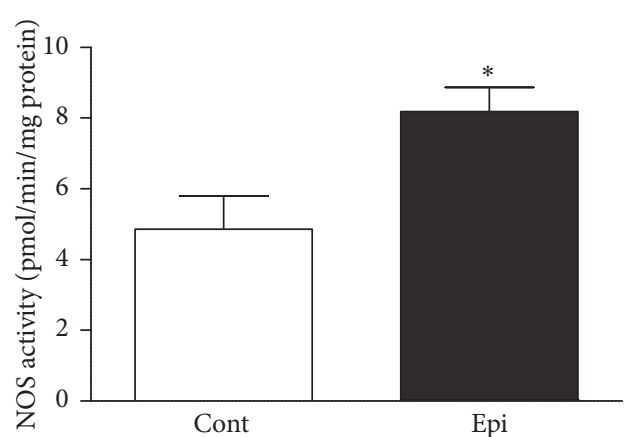

(b)

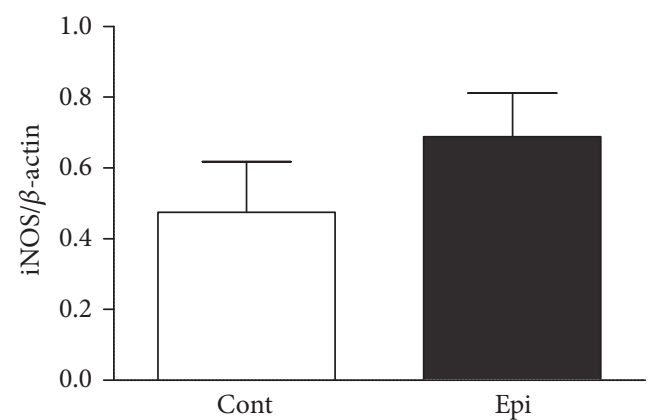

(d)

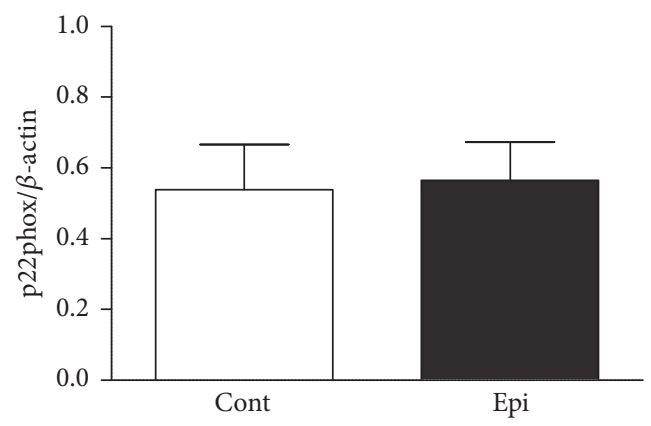

(f)

FIGURE 3: Effect of (-)-epicatechin treatment on superoxide production (a), nitric oxide synthase (NOS) activity (b), gene expression of neuronal NOS (nNOS, c), inducible NOS (iNOS, d), endothelial NOS (eNOS, e), and the p22phox subunit of nicotinamide adenine dinucleotide phosphate oxidase (f) in the left heart ventricle of spontaneously hypertensive rats. Values represent mean \pm SEM; $n=6-8$ for Cont and $n=8-10$ for Epi. ${ }^{*} p<0.05$ versus Cont group. Abbreviations: Cont: control group and Epi: (-)-epicatechin-treated group.

water and further metabolism after ingestion. The presence of Epi and/or its metabolites (e.g., $3^{\prime}$-O-methyl epicatechin and $4^{\prime}$-O-methyl epicatechin) in plasma as well as in the brain was detected previously after administration of the same dose of Epi as used in this study [41]. However, despite the fact that biologically active substance(s) may differ from Epi itself, this study demonstrates the significant biological effects of orally administered Epi. We used the given dose of Epi $(100 \mathrm{mg} / \mathrm{kg} / \mathrm{day})$, as we were interested in possible central effects of Epi, despite the fact that BP-lowering effect can be reached by lower doses. As the relatively high dose of Epi was used in this study, we determined creatinine, uric acid, and urea in plasma at the end of Epi treatment to reveal whether the given dose of Epi is safe or if it produces adverse side effects to kidneys. No signs of renal toxicity of the given dose of Epi were observed in our study (see Supplementary Materials available online at http://dx.doi.org/10.1155/2016/6949020).

The Epi-mediated prevention of hypertension development was associated with elevated plasma TAC and reduced superoxide production in the LHV and aortae of Epitreated rats. However, these findings were not associated with changes in the gene expression of the p22phox subunit of NADPH oxidase, one of the main sources of $\mathrm{O}_{2}{ }^{-{ }^{-}}$in the CVS. These findings support other studies in which the antioxidant capacity of Epi was associated either with activation of the enzymes involved in the antioxidant defense system [42] in the heart or with radical-scavenging properties in endothelial cells without affecting NADPH oxidase activity in vitro [43, $44]$. On the other hand, short-term Epi cotreatment reduced 


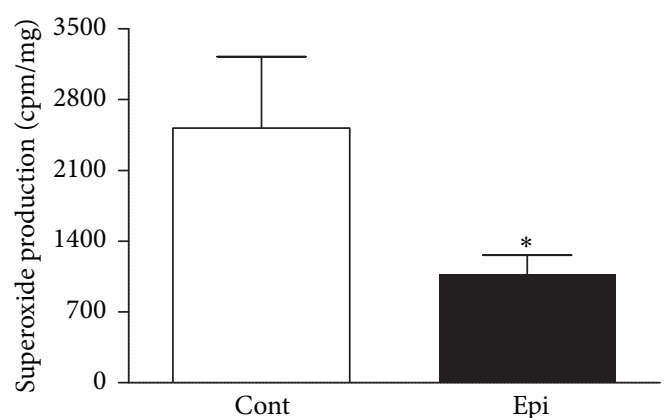

(a)

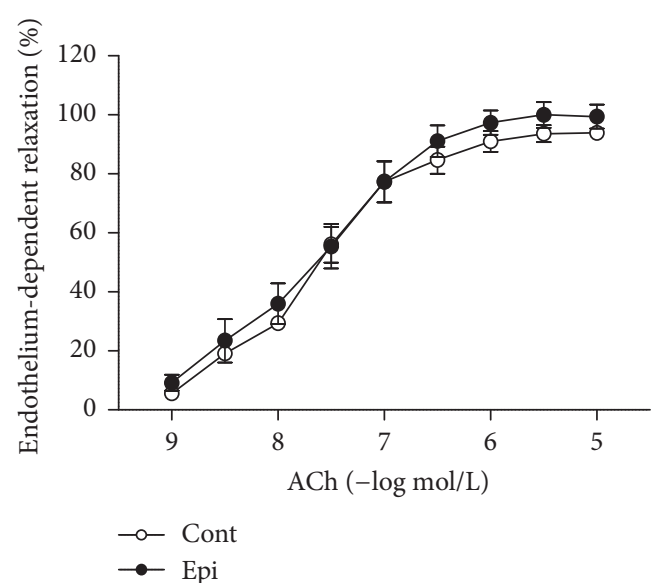

(c)

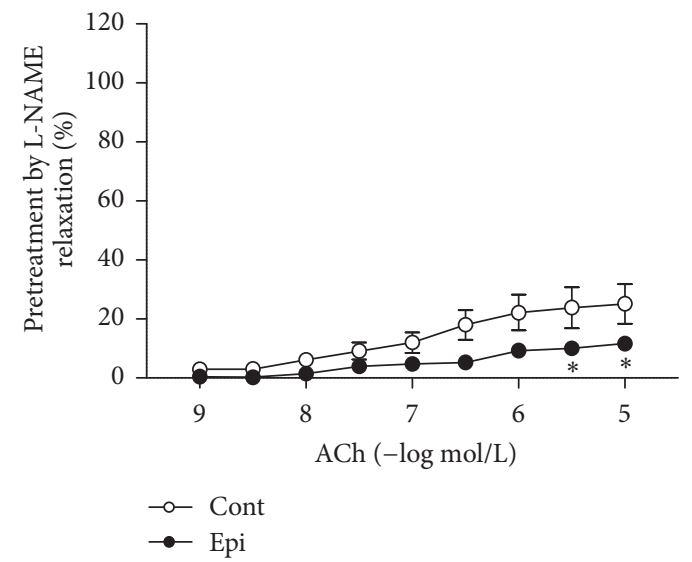

(e)

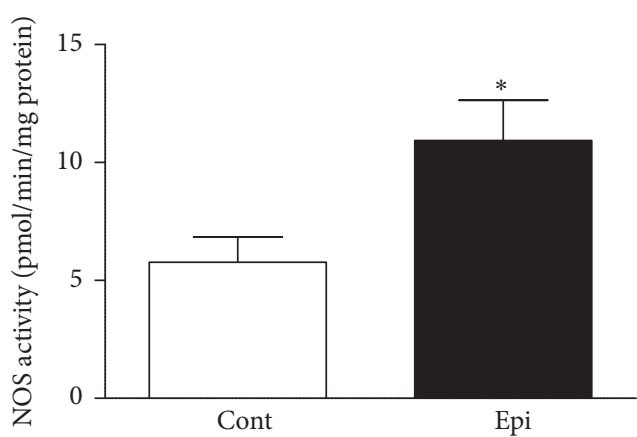

(b)

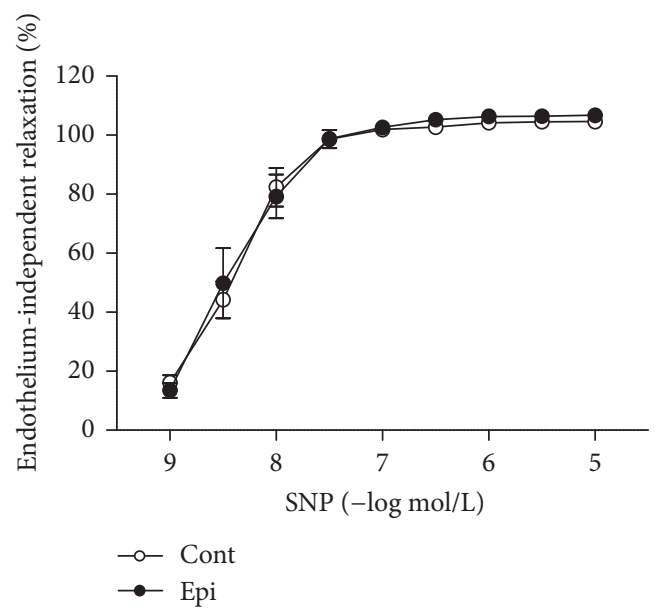

(d)

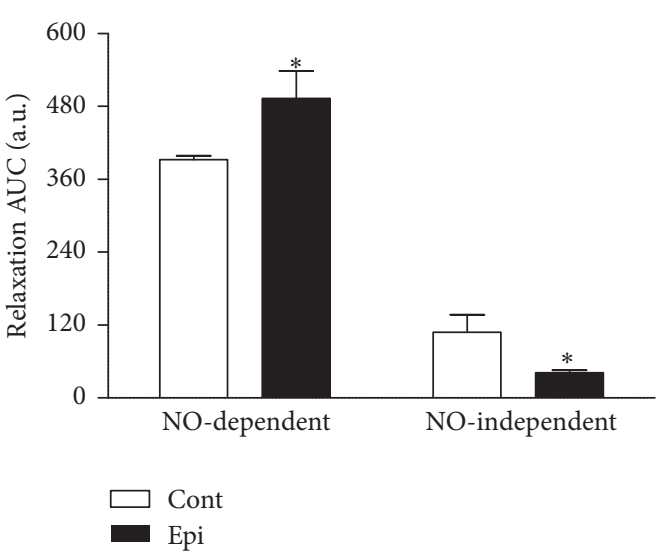

(f)

FIGURE 4: Effect of (-)-epicatechin treatment on superoxide production (a), NOS activity (b), endothelium-dependent relaxation induced by acetylcholine (c), endothelium-independent relaxation induced by SNP (d), inhibitory effect of L-NAME pretreatment ( $300 \mu \mathrm{mol} / \mathrm{L})$ on AChinduced relaxation (e), and NO-dependent and NO-independent components of relaxation (f) in the aorta of spontaneously hypertensive rats. Values represent mean \pm SEM; $n=6-8$ for Cont and $n=6-10$ for Epi. ${ }^{*} p<0.05$ versus Cont group. Abbreviations: ACh: acetylcholine, AUC: area under the curve, a.u.: arbitrary units, Cont: control group, Epi: (-)-epicatechin-treated group, L-NAME: $\mathrm{N}^{\mathrm{G}}$-nitro-L-arginine methyl ester, NO: nitric oxide, NOS: nitric oxide synthase, and SNP: sodium nitroprusside.

protein expression levels of the p47phox subunit of NADPH oxidase in the hearts of rats with L-NAME-induced hypertension [24] and in the renal cortex in fructose-fed rats [45], in contrast to our findings in a genetic model of hypertension. Regarding nitrosative damage, in vitro studies revealed that
Epi protected cells against peroxynitrite-induced damage [46, 47] similarly as we observed in vivo in blood.

In addition to the reduction in superoxide production and increased NOS activity in the aorta and LHV as well as reduced plasma nitrotyrosine concentration, increased aortic 

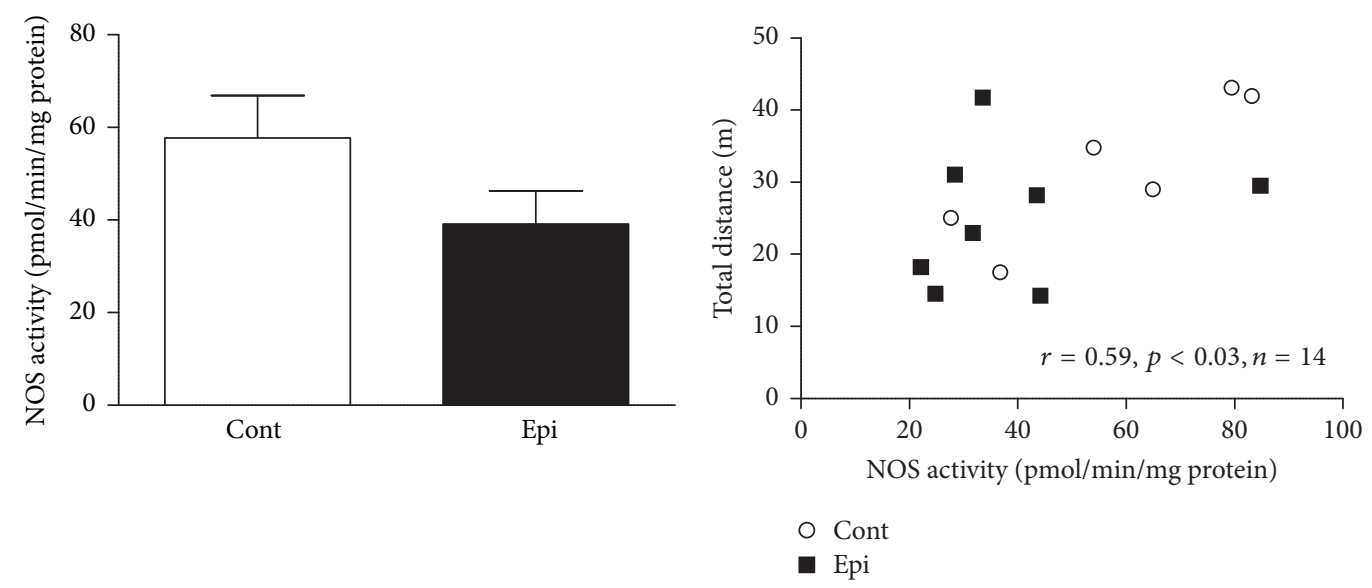

(a)
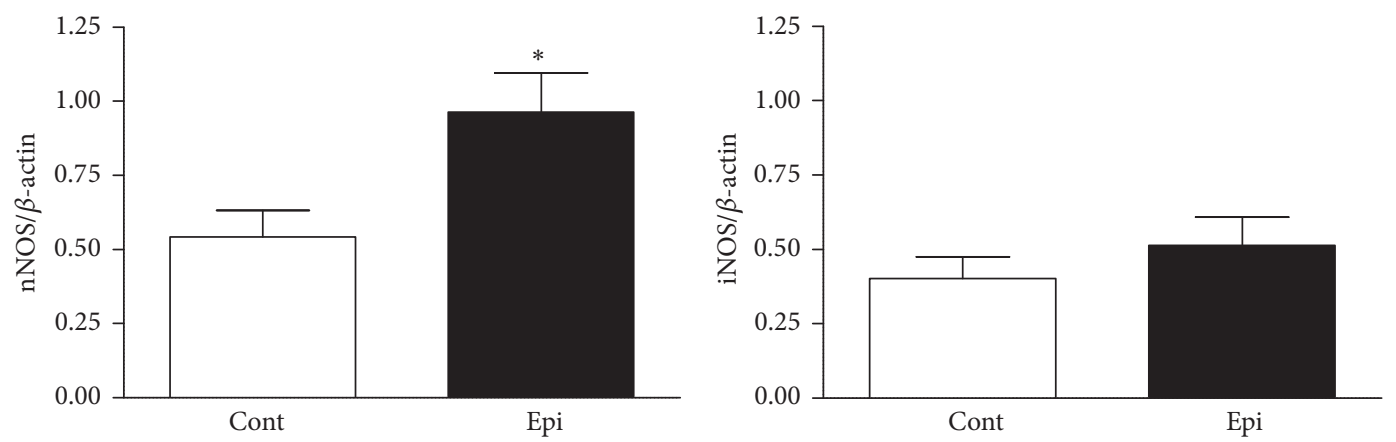

(c)

(d)
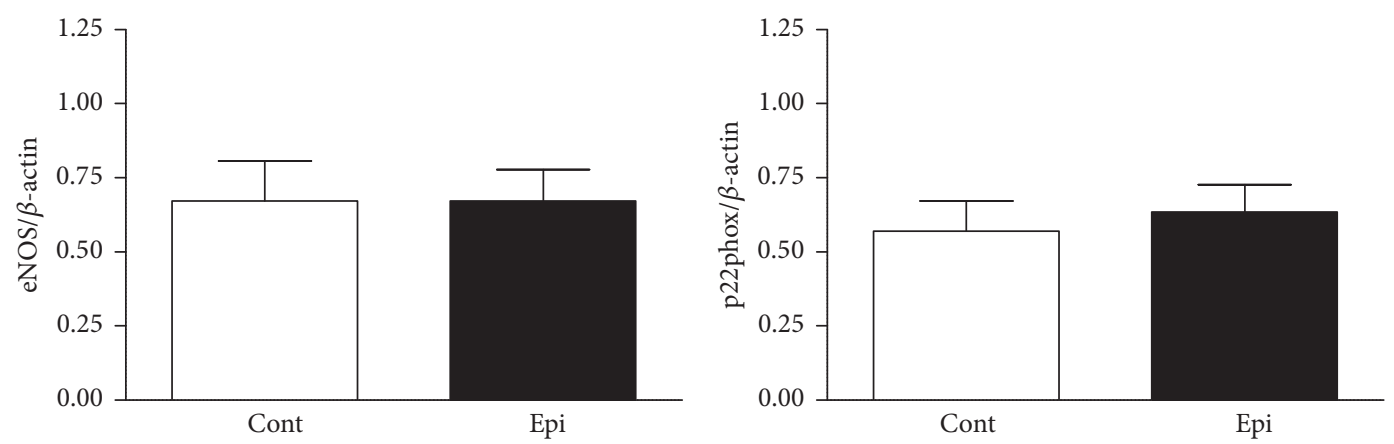

(e)

(f)

FIGURE 5: Effect of (-)-epicatechin treatment on nitric oxide synthase activity (a), correlation between total distance traveled in the openfield and nitric oxide synthase activity (b) and gene expression of nNOS (c), iNOS (d), eNOS (e), and the p22phox (f) in the brainstem of spontaneously hypertensive rats. Values represent mean \pm SEM; $n=6$ for Cont and $n=8-10$ for Epi. ${ }^{*} p<0.05$ versus Cont group. Abbreviations: Cont: control group, Epi: (-)-epicatechin-treated group, NOS: nitric oxide synthase, eNOS: endothelial NOS, iNOS: inducible NOS, nNOS: neuronal NOS, and p22phox: subunit of nicotinamide adenine dinucleotide phosphate oxidase.

endothelial NO-dependent relaxation also proofs better NO bioavailability in the CVS. Interestingly, no effect of Epi on $\mathrm{e} / \mathrm{i} / \mathrm{nNOS}$ gene expression in the LHV was found in this study, suggesting that Epi influences the catalytic properties of NOS but not its gene expression in the CVS. A similar mechanism was demonstrated previously in cultured endothelial cells [48] as well as in the cardiac tissue of L-NAME-treated rats [24]. Therefore, our study in a genetic model of spontaneous hypertension confirms the ability of Epi to increase the
CVS capacity for NO production resulting in elevated NO bioavailability; however, the involvement of individual NOS isoforms remains to be clarified.

Regarding vascular function, acute Epi administration induces both endothelium-dependent and endotheliumindependent relaxation in the isolated arteries of normotensive rats and in human arteries [49-51]. The Epiinduced endothelium-dependent relaxation in normotensive rats was primarily mediated by $\mathrm{NO}[49,50]$. Recent study 

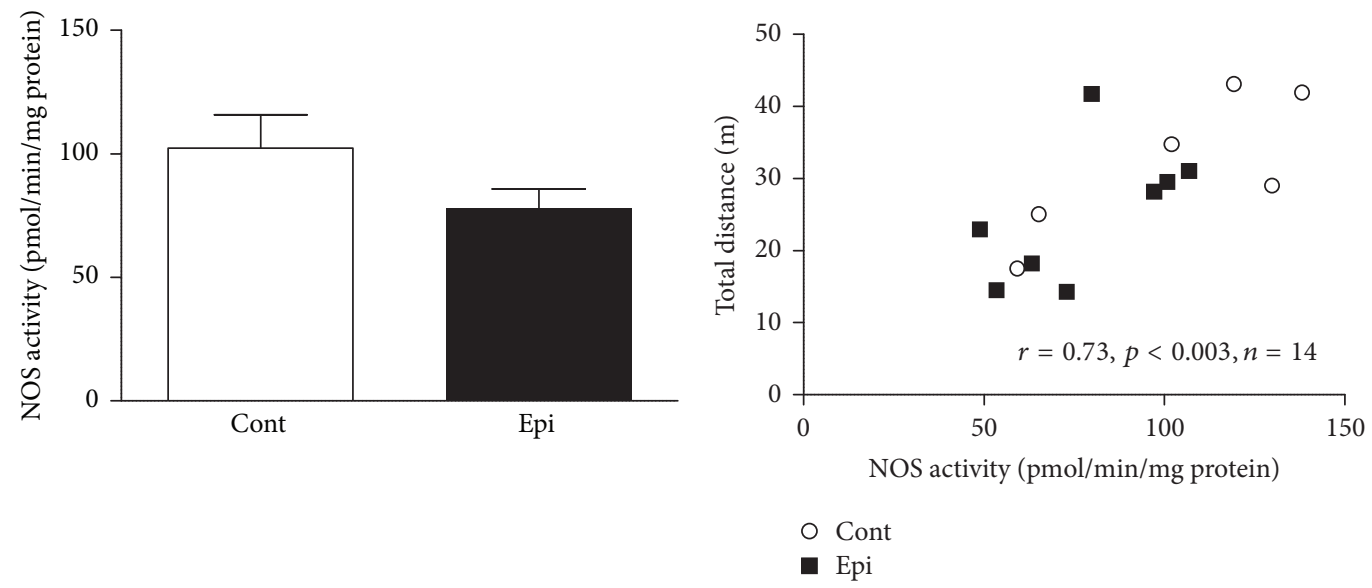

(a)
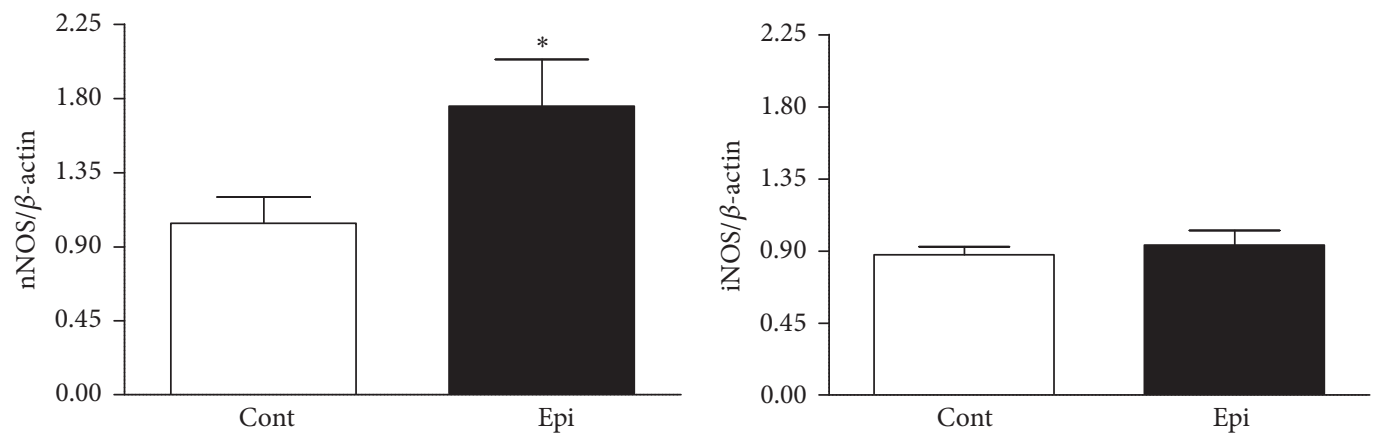

(c)

(d)
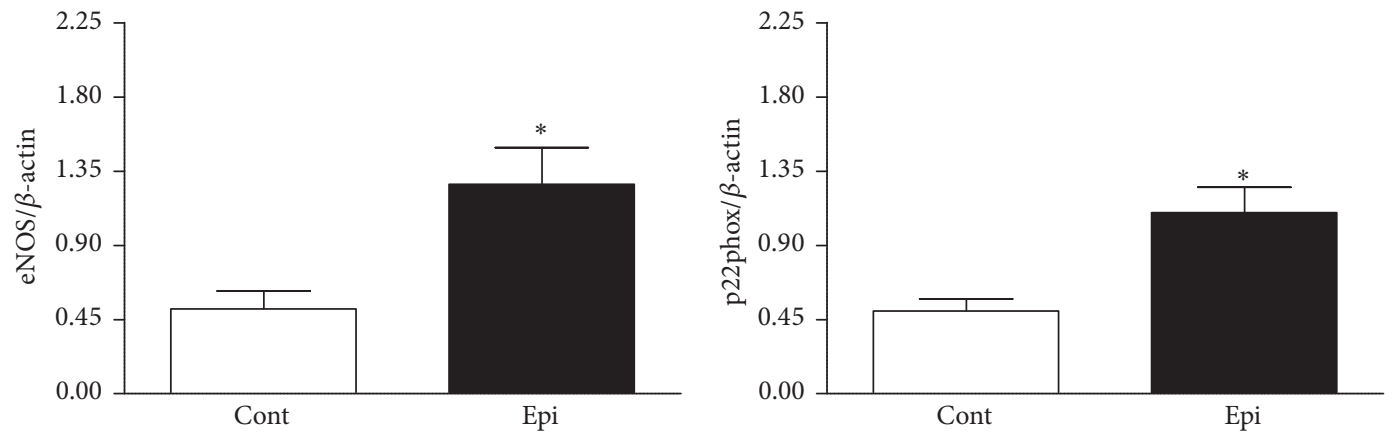

(e)

(f)

FIGURE 6: Effect of (-)-epicatechin treatment on nitric oxide synthase (NOS) activity (a), correlation between total distance traveled in the open-field and NOS activity (b) and gene expression of nNOS (c), iNOS (d), eNOS (e), and p22phox (f) in the cerebellum of spontaneously hypertensive rats. Values represent mean \pm SEM; $n=6$ for Cont and $n=8-10$ for Epi. ${ }^{*} p<0.05$ versus Cont group. Abbreviations: Cont: control group, Epi: (-)-epicatechin-treated group, eNOS: endothelial NOS, iNOS: inducible NOS, nNOS: neuronal NOS, and p22phox: subunit of nicotinamide adenine dinucleotide phosphate oxidase.

of Moreno-Ulloa et al. has suggested G protein-coupled estrogen receptor (GPER) as a potential mediator of Epi effects in vasculature, which was associated with elevated phosphorylation of eNOS in Wistar rats [52]. We have shown recently that relatively short-term (10-day) dietary administration of Epi reversed endothelial dysfunction in the femoral artery of adult SHR by enhancing the NO-dependent component of relaxation [27]. Similarly, in people with nevertreated essential hypertension, administering flavanol-rich dark chocolate (which has a high concentration of Epi) for two weeks normalized the NO-mediated endotheliumdependent relaxation in the brachial artery [53]. In this study, Epi elevated NOS activity in the aorta and enhanced the NOdependent component of $\mathrm{ACh}$-induced relaxation but failed 
to affect overall relaxation in peripubertal SHR. Yet despite the lack of an effect on overall relaxation in the aorta, the improvements in vascular NO bioavailability and the NOdependent component of relaxation observed in Epi-treated rats in this study may prevent vascular remodeling and reduce vascular wall stiffness [54], both of which are observed in hypertension [55-57].

Furthermore, the increased level of erythrocyte deformability observed in this study suggests improvements in blood flow as well as oxygenation in individual organs, similarly as has been recently observed in humans after two-week cocoa flavanol intake [58]. As erythrocytes contain functional eNOS and NO increases their deformability [59], it is plausible that the positive health effects of Epi are associated with the NOrelated modulation of red blood cell properties [60]. Collectively, these observations in various experimental conditions both in vitro and in vivo suggest multiple mechanisms for the cardioprotective effects of Epi that are associated with improved NO bioavailability in the heart and vasculature as well as with enhancement of mechanical properties of the red blood cells.

In addition to the cardiovascular effects of Epi, our study pointed also to possible central effects. As mentioned above, Epi can cross the BBB $[28,29,41]$. Moreover, BBB was shown to be damaged in hypertension, specifically, in the brainstem and cerebellum [56, 61]. We chose these areas of the brain to focus on because the cerebellum integrates the neural control of movement and plays a role in the pathogenesis of ADHD [62]. The brainstem was selected as it is a part of the brain involved in the control of bodily motor function, in addition to the regulation of cardiac and respiratory functions.

In humans, the consumption of natural polyphenols, including cocoa flavanols, results in an acute improvement in visual and cognitive functions $[63,64]$, which may be relevant in the treatment of ADHD. Indeed, Pycnogenol ${ }^{\circledR}$, a polyphenol extract from the bark of the French maritime pine, significantly reduces hyperactivity and improves attention, visual-motor coordination, and concentration in children with ADHD [65]. However, to our knowledge, the effect of Epi on ADHD symptoms has not yet been investigated in humans. Several studies in rodents have demonstrated the variable effects of flavanols on behavior. In Wistar rats, a single dose of cacao mass showed anxiolytic effects, but 2week consumption did not reduce anxiety-related behavior. Locomotor activity in the OF was unaffected in those rats [66]. Two-week cocoa polyphenolic extract treatment had an antidepressant-like effect in Wistar-Unilever rats subjected to a forced-swim test without accompanying changes in locomotion in the OF [67]. In adult C57BL/6 mice, Epi had an anxiolytic effect as represented by an elevated ratio of distance traveled and time spent in the central zone of the OF compared to periphery [68]. However, it has to be noted that all of these studies were performed in normotensive rodents. We used SHR, which are known to be locomotor hyperactive with high levels of exploratory activity and reduced levels of anxiety compared to normotensive rat strains $[5,69,70]$. In our study, Epi administration attenuated locomotor hyperactivity as determined by decreases in the total distance traveled and the average speed of movement as well as by increases in total immobility. Epi also deceptively elevated anxiety in the OF, as suggested by reductions in total distance traveled and time spent in the central zone (in both absolute and relative values) and increased time spent in the corners. However, considering the innate hyperactivity and low anxiety levels of control SHR, Epi, in fact, corrected their behavioral abnormalities. These alterations were not associated with changes in NOS activity in the selected brain areas. However, in contrast to our findings in the LHV, we observed increased nNOS gene expression in both areas of the brain investigated here; eNOS gene expression increased only in the cerebellum. Interestingly, NOS activity in the brainstem and cerebellum correlated positively with locomotor activity and negatively with anxiety level (determined as a reduction in the central zone distance traveled) in the $\mathrm{OF}$. These correlations were stronger in the cerebellum, suggesting that cerebellar NO-dependent mechanisms are more significantly involved in modulation of locomotor activity in young SHR. Yet, the studies performed to date in rats and in humans have demonstrated the considerable variability of findings on the role of $\mathrm{NO}$ in the modulation of behavior as well as the varying effects of $\mathrm{NO}$ in different neuroanatomical structures of the brain, which might even be antagonistic on the behavioral level $[8,34]$.

It is of interest that gene expression levels for the p22phox subunit of NADPH oxidase were increased in the cerebellum following Epi treatment, which is in contrast to the findings reported for the CVS in different animal models of hypertension [24-26]. If the Epi-induced upregulation of NADPH oxidase gene expression was to be followed by translation into functional enzyme, the abovementioned antioxidant effects of Epi could still maintain ROS at physiological levels. Our review of the literature did not reveal any study that has investigated the effect of subchronic Epi treatment on e/i/nNOS or p22phox NADPH oxidase subunit gene expression or activity in the CVS or brain of SHR. Yet our findings suggest that Epi exerts tissue-specific effects on the expression of individual NOS isoforms and NADPH oxidase subunits in SHR. These effects may not correlate with enzyme activity levels in the corresponding tissue [71].

The simultaneous prevention of BP increase and reduced hyperactivity of SHR observed in this study suggest the possibility of a common mechanism(s) underlying both pathologies. One possible mechanism is a reduction in noradrenergic neurotransmission, which is elevated in SHR and associated with high blood pressure and locomotor hyperactivity [62, 72]. In Epi-treated SHR rats, noradrenergic hyperfunction may be diminished by presynaptic $\alpha_{2}$-autoreceptor-mediated feedback $[62,73]$, the improvement of calcium signaling $[62,74]$, and/or increases in bioavailability of NO [75]. These effects may prevent hypertension development and decrease locomotion in young SHR. Another plausible mechanism is the improvement of regional cerebral blood flow, as its alterations were observed in SHR and children with ADHD $[62,76]$ and flavanol-rich cocoa consumption improved it in older healthy volunteers [77].

Although our study brought interesting results related to simultaneous prevention of hypertension and reduction 
of behavioral hyperactivity in juvenescent rats, there are certain limitations of this study. Firstly, NO production, gene expressions, and vascular function were determined in the aorta. These parameters may differ in smaller arteries, so the effect of Epi, especially in the small resistance arteries, needs to be investigated. Secondly, we did not determine Epi and/or Epi metabolites levels in blood, NOS phosphorylation, and involvement of GPER receptors. Thus, further studies are needed to elucidate the exact bioactive substance(s) and the exact site(s) of action of orally administered Epi in preventing and treating hypertension and behavioral hyperactivity in young subjects.

\section{Conclusion}

In conclusion, the results presented here showed that oral Epi treatment significantly prevented BP increase and reduced behavioral hyperactivity in young SHR. The mechanism underlying the positive effects of Epi observed in this study was related to improved cardiovascular NO bioavailability, due to elevated NOS activity and reduced $\mathrm{O}_{2}{ }^{--}$levels in the CVS concurrently with elevations in plasma antioxidant capacity as well as red blood cell deformability. Altogether, these beneficial alterations could result in reduced sympathetic tone and improved cerebrovascular blood flow and tissue oxygenation, resulting in the prevention of hypertension and the reduction of locomotor hyperactivity. The results of this study may be relevant in pharmacological approaches to the prevention and treatment of hypertension and ADHD comorbidity in young subjects with a significant family history of hypertension. Our data also suggest tissuespecific influences of Epi in SHR that should be taken into account in evaluating the overall effects of Epi-containing foods.

\section{Competing Interests}

All authors have no potential financial or ethical competing interests regarding the contents of the submission.

\section{Acknowledgments}

The authors thank Mrs. J. Petova and M. Kovacsova for their technical assistance. This study was supported by Grants VEGA 2/0084/14, VEGA 1/0032/14, and APVV-0523-10. The infrastructure used in this study was partially supported by the "ITMS 26240120020-Establishment of the Centre for the Research on Composite Materials for Structural, Engineering and Medical Applications-CEKOMAT II" project.

\section{References}

[1] B. Falkner, "Hypertension in children and adolescents: epidemiology and natural history," Pediatric Nephrology, vol. 25, no. 7, pp. 1219-1224, 2010.

[2] E. G. Willcutt, "The prevalence of DSM-IV attention-deficit/ hyperactivity disorder: a meta-analytic review," Neurotherapeutics, vol. 9, no. 3, pp. 490-499, 2012.
[3] H. R. Adams, P. G. Szilagyi, L. Gebhardt, and M. B. Lande, "Learning and attention problems among children with pediatric primary hypertension," Pediatrics, vol. 126, no. 6, pp. e1425-e1429, 2010.

[4] G. Cicco and A. Pirrelli, "Red blood cell (RBC) deformability, $\mathrm{RBC}$ aggregability and tissue oxygenation in hypertension," Clinical Hemorheology and Microcirculation, vol. 21, no. 3-4, pp. 169-177, 1999.

[5] T. Sagvolden, E. D. Hendley, and S. Knardahl, "Behavior of hypertensive and hyperactive rat strains: hyperactivity is not unitarily determined," Physiology \& Behavior, vol. 52, no. 1, pp. 49-57, 1992.

[6] T. Sagvolden and E. B. Johansen, "Rat models of ADHD," in Behavioral Neuroscience of Attention Deficit Hyperactivity Disorder and Its Treatment, pp. 301-315, Springer, Berlin, Germany, 2011.

[7] V. Volke, A. Soosaar, S. Kõks, M. Bourin, P. T. Männistö, and E. Vasar, "7-Nitroindazole, a nitric oxide synthase inhibitor, has anxiolytic-like properties in exploratory models of anxiety," Psychopharmacology, vol. 131, no. 4, pp. 399-405, 1997.

[8] F. Freudenberg, A. Alttoa, and A. Reif, "Neuronal nitric oxide synthase (NOS1) and its adaptor, NOS1AP, as a genetic risk factors for psychiatric disorders," Genes, Brain and Behavior, vol. 14, no. 1, pp. 46-63, 2015.

[9] M. Majzunova, I. Dovinova, M. Barancik, and J. Y. H. Chan, "Redox signaling in pathophysiology of hypertension," Journal of Biomedical Science, vol. 20, no. 1, article 69, 2013.

[10] F. Ng, M. Berk, O. Dean, and A. I. Bush, "Oxidative stress in psychiatric disorders: evidence base and therapeutic implications," The International Journal of Neuropsychopharmacology, vol. 11, no. 6, pp. 851-876, 2008.

[11] J. Bouayed, H. Rammal, and R. Soulimani, "Oxidative stress and anxiety: relationship and cellular pathways," Oxidative Medicine and Cellular Longevity, vol. 2, no. 2, pp. 63-67, 2009.

[12] T. J. Guzik, N. E. J. West, R. Pillai, D. P. Taggart, and K. M. Channon, "Nitric oxide modulates superoxide release and peroxynitrite formation in human blood vessels," Hypertension, vol. 39, no. 6, pp. 1088-1094, 2002.

[13] P. Ferdinandy, H. Danial, I. Ambrus, R. A. Rothery, and R. Schulz, "Peroxynitrite is a major contributor to cytokine-induced myocardial contractile failure," Circulation Research, vol. 87, no. 3, pp. 241-247, 2000.

[14] Z. Szilvássy, T. Csont, T. Páli, M.-T. Droy-Lefaix, and P. Ferdinandy, "Nitric oxide, peroxynitrite and cGMP in atherosclerosis-induced hypertension in rabbits: beneficial effects of cicletanine," Journal of Vascular Research, vol. 38, no. 1, pp. 3946, 2001.

[15] C. G. Fraga and P. Oteiza, "Flavanols and vascular health: molecular mechanisms to build evidence-based recommendations," Free Radical Biology and Medicine, vol. 75, supplement 1, p. S12, 2014.

[16] V. Schini-Kerth, "Role of polyphenols in improving endothelial dysfunction in diabetes," Free Radical Biology and Medicine, vol. 75, no. 1, pp. S11-S12, 2014.

[17] B. Buijsse, E. J. M. Feskens, F. J. Kok, and D. Kromhout, "Cocoa intake, blood pressure, and cardiovascular mortality: The Zutphen Elderly Study," Archives of Internal Medicine, vol. 166 , no. 4, pp. 411-417, 2006.

[18] M. L. McCullough, K. Chevaux, L. Jackson et al., "Hypertension, the Kuna, and the epidemiology of flavanols," Journal of Cardiovascular Pharmacology, vol. 47, supplement 2, pp. S103S109, 2006. 
[19] S. Desch, J. Schmidt, D. Kobler et al., "Effect of cocoa products on blood pressure: systematic review and meta-analysis," American Journal of Hypertension, vol. 23, no. 1, pp. 97-103, 2010.

[20] K. Ried, T. Sullivan, P. Fakler, O. R. Frank, and N. P. Stocks, "Does chocolate reduce blood pressure? A meta-analysis," BMC Medicine, vol. 8, article 39, 2010.

[21] S. Ellinger, A. Reusch, P. Stehle, and H.-P. Helfrich, "Epicatechin ingested via cocoa products reduces blood pressure in humans: a nonlinear regression model with a Bayesian approach," American Journal of Clinical Nutrition, vol. 95, no. 6, pp. 1365-1377, 2012.

[22] H. Schroeter, C. Heiss, J. Balzer et al., “(-)-Epicatechin mediates beneficial effects of flavanol-rich cocoa on vascular function in humans," Proceedings of the National Academy of Sciences of the United States of America, vol. 103, no. 4, pp. 1024-1029, 2006.

[23] M. K. Piskula and J. Terao, "Accumulation of (-)-epicatechin metabolites in rat plasma after oral administration and distribution of conjugation enzymes in rat tissues," Journal of Nutrition, vol. 128, no. 7, pp. 1172-1178, 1998.

[24] B. Piotrkowski, V. Calabró, M. Galleano, and C. G. Fraga, "(-)-Epicatechin prevents alterations in the metabolism of superoxide anion and nitric oxide in the hearts of L-NAMEtreated rats," Food and Function, vol. 6, no. 1, pp. 155-161, 2015.

[25] M. C. Litterio, M. A. Vazquez Prieto, A. M. Adamo et al., "(-)-Epicatechin reduces blood pressure increase in highfructose-fed rats: effects on the determinants of nitric oxide bioavailability," Journal of Nutritional Biochemistry, vol. 26, no. 7, pp. 745-751, 2015.

[26] M. Gómez-Guzmán, R. Jiménez, M. Sánchez et al., "Epicatechin lowers blood pressure, restores endothelial function, and decreases oxidative stress and endothelin-1 and NADPH oxidase activity in DOCA-salt hypertension," Free Radical Biology and Medicine, vol. 52, no. 1, pp. 70-79, 2012.

[27] M. Galleano, I. Bernatova, A. Puzserova et al., "Epicatechin reduces blood pressure and improves vasorelaxation in spontaneously hypertensive rats by NO-mediated mechanism," IUBMB Life, vol. 65, no. 8, pp. 710-715, 2013.

[28] L. Wu, Q.-L. Zhang, X.-Y. Zhang et al., "Pharmacokinetics and blood-brain barrier penetration of (+)-Catechin and (-)Epicatechin in rats by microdialysis sampling coupled to highperformance liquid chromatography with chemiluminescence detection," Journal of Agricultural and Food Chemistry, vol. 60, no. 37, pp. 9377-9383, 2012.

[29] A. Faria, D. Pestana, D. Teixeira et al., "Insights into the putative catechin and epicatechin transport across blood-brain barrier," Food \& Function, vol. 2, no. 1, pp. 39-44, 2011.

[30] D. Mastroiacovo, C. Kwik-Uribe, D. Grassi et al., "Cocoa flavanol consumption improves cognitive function, blood pressure control, and metabolic profile in elderly subjects: the cocoa, cognition, and aging (CoCoA) study - a randomized controlled trial," American Journal of Clinical Nutrition, vol. 101, no. 3, pp. 538-548, 2015.

[31] I. Bernatova, M. P. Key, J. B. Lucot, and M. Morris, "Circadian differences in stress-induced pressor reactivity in mice," Hypertension, vol. 40, no. 5, pp. 768-773, 2002.

[32] Y. L. Su, L. K. Leung, Y. Huang, and Z.-Y. Chen, "Stability of tea theaflavins and catechins," Food Chemistry, vol. 83, no. 2, pp. 189-195, 2003.

[33] A. Puzserova, P. Slezak, P. Balis, and I. Bernatova, "Long-term social stress induces nitric oxide-independent endothelial dysfunction in normotensive rats," Stress, vol. 16, no. 3, pp. 331-339, 2013.
[34] N. Sestakova, A. Puzserova, M. Kluknavsky, and I. Bernatova, "Determination of motor activity and anxiety-related behaviour in rodents: methodological aspects and role of nitric oxide," Interdisciplinary Toxicology, vol. 6, no. 3, pp. 126-135, 2013.

[35] A. Mataseje, I. Beder, M. Kittova, J. Okkelova, and R. Vazan, "The assessment of erythrocyte deformability by filtration rate," Bratislavské Lekárske Listy, vol. 104, no. 4-5, pp. 158-160, 2003.

[36] R. Re, N. Pellegrini, A. Proteggente, A. Pannala, M. Yang, and C. Rice-Evans, "Antioxidant activity applying an improved ABTS radical cation decolorization assay," Free Radical Biology and Medicine, vol. 26, no. 9-10, pp. 1231-1237, 1999.

[37] P. Slezak, A. Puzserova, P. Balis et al., "Genotype-related effect of crowding stress on blood pressure and vascular function in young female rats," BioMed Research International, vol. 2014, Article ID 413629, 11 pages, 2014.

[38] S. Cacanyiova, F. Kristek, M. Malekova, and K. Ondrias, "Effect of chronic neuronal nitric oxide-synthase inhibition on arterial function and structure in spontaneously hypertensive rats," Journal of Physiology and Pharmacology, vol. 63, no. 1, pp. 23-28, 2012.

[39] J. Zicha and J. Kuneš, "Ontogenetic aspects of hypertension development: analysis in the rat," Physiological Reviews, vol. 79, no. 4, pp. 1227-1282, 1999.

[40] M. Cebova and F. Kristek, "Age-dependent ultrastructural changes of coronary artery in spontaneously hypertensive rats," General Physiology and Biophysics, vol. 30, no. 4, pp. 364-372, 2011.

[41] M. M. Abd El Mohsen, G. Kuhnle, A. R. Rechner et al., "Uptake and metabolism of epicatechin and its access to the brain after oral ingestion," Free Radical Biology and Medicine, vol. 33, no. 12, pp. 1693-1702, 2002.

[42] S. D. Quine and P. S. Raghu, "Effects of (-)-epicatechin, a flavonoid on lipid peroxidation and antioxidants in streptozotocin-induced diabetic liver, kidney and heart," Pharmacological Reports, vol. 57, no. 5, pp. 610-615, 2005.

[43] Y. Steffen, C. Gruber, T. Schewe, and H. Sies, "Mono-O-methylated flavanols and other flavonoids as inhibitors of endothelial NADPH oxidase," Archives of Biochemistry and Biophysics, vol. 469, no. 2, pp. 209-219, 2008.

[44] E. J. B. Ruijters, A. R. Weseler, C. Kicken, G. R. M. M. Haenen, and A. Bast, "The flavanol (-)-epicatechin and its metabolites protect against oxidative stress in primary endothelial cells via a direct antioxidant effect," European Journal of Pharmacology, vol. 715, no. 1-3, pp. 147-153, 2013.

[45] P. D. Prince, C. R. Lanzi, J. E. Toblli et al., "Dietary (-)epicatechin mitigates oxidative stress, NO metabolism alterations, and inflammation in renal cortex from fructose-fed rats," Free Radical Biology and Medicine, vol. 90, pp. 35-46, 2016.

[46] P. Schroeder, L.-O. Klotz, and H. Sies, "Amphiphilic properties of (-)-epicatechin and their significance for protection of cells against peroxynitrite," Biochemical and Biophysical Research Communications, vol. 307, no. 1, pp. 69-73, 2003.

[47] P. Schroeder, L.-O. Klotz, D. P. Buchczyk, C. D. Sadik, T. Schewe, and H. Sies, "Epicatechin selectively prevents nitration but not oxidation reactions of peroxynitrite," Biochemical and Biophysical Research Communications, vol. 285, no. 3, pp. 782-787, 2001.

[48] I. Ramirez-Sanchez, L. Maya, G. Ceballos, and F. Villarreal, "(-)-Epicatechin activation of endothelial cell endothelial nitric oxide synthase, nitric oxide, and related signaling pathways," Hypertension, vol. 55, no. 6, pp. 1398-1405, 2010.

[49] Y. Huang, N. W. K. Chan, C. W. Lau, X. Q. Yao, F. L. Chan, and Z. Y. Chen, "Involvement of endothelium/nitric oxide in 
vasorelaxation induced by purified green tea (-)epicatechin," Biochimica et Biophysica Acta-General Subjects, vol. 1427, no. 2, pp. 322-328, 1999.

[50] A. Aggio, D. Grassi, E. Onori et al., "Endothelium/nitric oxide mechanism mediates vasorelaxation and counteracts vasoconstriction induced by low concentration of flavanols," European Journal of Nutrition, vol. 52, no. 1, pp. 263-272, 2013.

[51] A. Novakovic, M. Marinko, A. Vranic et al., "Mechanisms underlying the vasorelaxation of human internal mammary artery induced by (-)-epicatechin," European Journal of Pharmacology, vol. 762, pp. 306-312, 2015.

[52] A. Moreno-Ulloa, D. Mendez-Luna, E. Beltran-Partida et al., "The effects of (-)-epicatechin on endothelial cells involve the G protein-coupled estrogen receptor (GPER)," Pharmacological Research, vol. 100, pp. 309-320, 2015.

[53] D. Grassi, S. Necozione, C. Lippi et al., "Cocoa reduces blood pressure and insulin resistance and improves endotheliumdependent vasodilation in hypertensives," Hypertension, vol. 46, no. 2, pp. 398-405, 2005.

[54] D. Grassi, G. Desideri, S. Necozione et al., "Cocoa consumption dose-dependently improves flow-mediated dilation and arterial stiffness decreasing blood pressure in healthy individuals," Journal of Hypertension, vol. 33, no. 2, pp. 294-303, 2015.

[55] M. Safar, P. Chamiot-Clerc, G. Dagher, and J. F. Renaud, "Pulse pressure, endothelium function, and arterial stiffness in spontaneously hypertensive rats," Hypertension, vol. 38, no. 6, pp. 14161421, 2001.

[56] P. W. Pires, C. M. D. Ramos, N. Matin, and A. M. Dorrance, "The effects of hypertension on the cerebral circulation," American Journal of Physiology-Heart and Circulatory Physiology, vol. 304, no. 12, pp. H1598-H1614, 2013.

[57] E. N. T. P. Bakker, G. Groma, L. J. A. Spijkers et al., "Heterogeneity in arterial remodeling among sublines of spontaneously hypertensive rats," PLoS ONE, vol. 9, no. 9, article e107998, 2014.

[58] C. Heiss, R. Sansone, H. Karimi et al., "Impact of cocoa flavanol intake on age-dependent vascular stiffness in healthy men: a randomized, controlled, double-masked trial," Age, vol. 37, no. 3, article 56, 2015.

[59] P. Kleinbongard, R. Schulz, T. Rassaf et al., "Red blood cells express a functional endothelial nitric oxide synthase," Blood, vol. 107, no. 7, pp. 2943-2951, 2006.

[60] O. Schnorr, T. Brossette, T. Y. Momma et al., "Cocoa flavanols lower vascular arginase activity in human endothelial cells in vitro and in erythrocytes in vivo," Archives of Biochemistry and Biophysics, vol. 476, no. 2, pp. 211-215, 2008.

[61] W. G. Mayhan, F. M. Faraci, and D. D. Heistad, "Disruption of the blood-brain barrier in cerebrum and brain stem during acute hypertension," American Journal of Physiology-Heart and Circulatory Physiology, vol. 251, no. 6, pp. H1171-H1175, 1986.

[62] V. A. Russell, "Neurobiology of animal models of attentiondeficit hyperactivity disorder," Journal of Neuroscience Methods, vol. 161, no. 2, pp. 185-198, 2007.

[63] D. T. Field, C. M. Williams, and L. T. Butler, "Consumption of cocoa flavanols results in an acute improvement in visual and cognitive functions," Physiology \& Behavior, vol. 103, no. 3-4, pp. 255-260, 2011.

[64] F. Jagla and O. Pechanova, "Age-related cognitive impairment as a sign of geriatric neurocardiovascular interactions: may polyphenols play a protective role?" Oxidative Medicine and Cellular Longevity, vol. 2015, Article ID 721514, 8 pages, 2015.
[65] J. Trebatická, S. Kopasová, Z. Hradečná et al., "Treatment of ADHD with French maritime pine bark extract, Pycnogenol ${ }^{\circledR,}$," European Child \& Adolescent Psychiatry, vol. 15, no. 6, pp. 329335, 2006.

[66] T. Yamada, Y. Yamada, Y. Okano, T. Terashima, and H. Yokogoshi, "Anxiolytic effects of short- and long-term administration of cacao mass on rat elevated T-maze test," The Journal of Nutritional Biochemistry, vol. 20, no. 12, pp. 948-955, 2009.

[67] M. Messaoudi, J.-F. Bisson, A. Nejdi, P. Rozan, and H. Javelot, "Antidepressant-like effects of a cocoa polyphenolic extract in Wistar-Unilever rats," Nutritional Neuroscience, vol. 11, no. 6, pp. 269-276, 2008.

[68] T. P. Stringer, D. Guerrieri, C. Vivar, and H. van Praag, "Plantderived flavanol (-)epicatechin mitigates anxiety in association with elevated hippocampal monoamine and BDNF levels, but does not influence pattern separation in mice," Translational Psychiatry, vol. 5, article e493, 2015.

[69] A. Ramos, O. Berton, P. Mormède, and F. Chaouloff, "A multiple-test study of anxiety-related behaviours in six inbred rat strains," Behavioural Brain Research, vol. 85, no. 1, pp. 57-69, 1997.

[70] C. Gentsch, M. Lichtsteiner, and H. Feer, "Open field and elevated plus-maze: a behavioural comparison between spontaneously hypertensive (SHR) and Wistar-Kyoto (WKY) rats and the effects of chlordiazepoxide," Behavioural Brain Research, vol. 25, no. 2, pp. 101-107, 1987.

[71] S. Miyamoto, A. Ochiai, N. Boku et al., "Discrepancies between the gene expression, protein expression, and enzymatic activity of thymidylate synthase and dihydropyrimidine dehydrogenase in human gastrointestinal cancers and adjacent normal mucosa," International Journal of Oncology, vol. 18, no. 4, pp. 705-713, 2001.

[72] N. Herring, C. W. Lee, N. Sunderland, K. Wright, and D. J. Paterson, "Pravastatin normalises peripheral cardiac sympathetic hyperactivity in the spontaneously hypertensive rat," Journal of Molecular and Cellular Cardiology, vol. 50, no. 1, pp. 99-106, 2011.

[73] B. Langen and R. Dost, "Comparison of SHR, WKY and Wistar rats in different behavioural animal models: effect of dopamine D1 and alpha2 agonists," ADHD Attention Deficit and Hyperactivity Disorders, vol. 3, no. 1, pp. 1-12, 2011.

[74] N. Kumar, R. Kant, P. K. Maurya, and S. I. Rizvi, "Concentration dependent effect of (-)-epicatechin on $\mathrm{Na}^{+} / \mathrm{K}^{+}$-ATPase and $\mathrm{Ca}^{2+}$-ATPase inhibition induced by free radicals in hypertensive patients: comparison with L-ascorbic acid," Phytotherapy Research, vol. 26, no. 11, pp. 1644-1647, 2012.

[75] J. Török, "Participation of nitric oxide in different models of experimental hypertension," Physiological Research, vol. 57, no. 6, pp. 813-825, 2008.

[76] J. F. Danker and T. Q. Duong, "Quantitative regional cerebral blood flow MRI of animal model of attention-deficit/ hyperactivity disorder," Brain Research, vol. 1150, no. 1, pp. 217224, 2007.

[77] F. A. Sorond, L. A. Lipsitz, N. K. Hollenberg, and N. D. L. Fisher, "Cerebral blood flow response to flavanol-rich cocoa in healthy elderly humans," Neuropsychiatric Disease and Treatment, vol. 4, no. 2, pp. 433-440, 2008. 


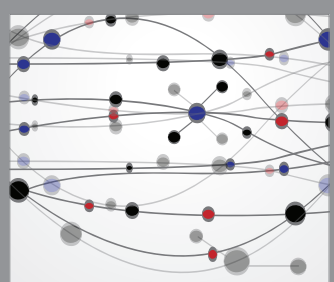

The Scientific World Journal
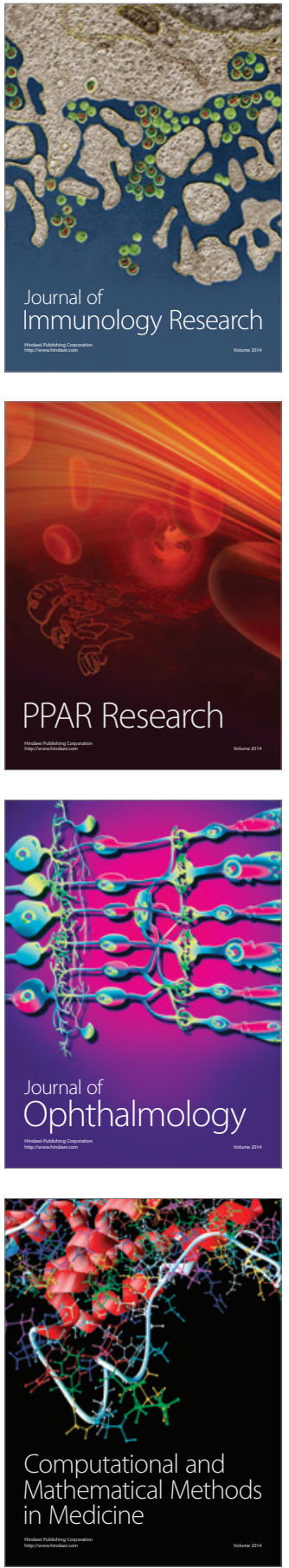

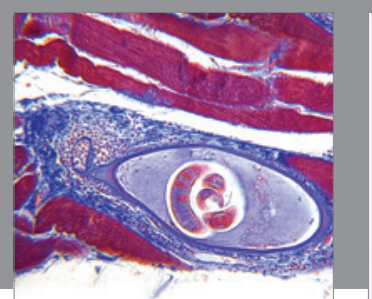

Gastroenterology Research and Practice

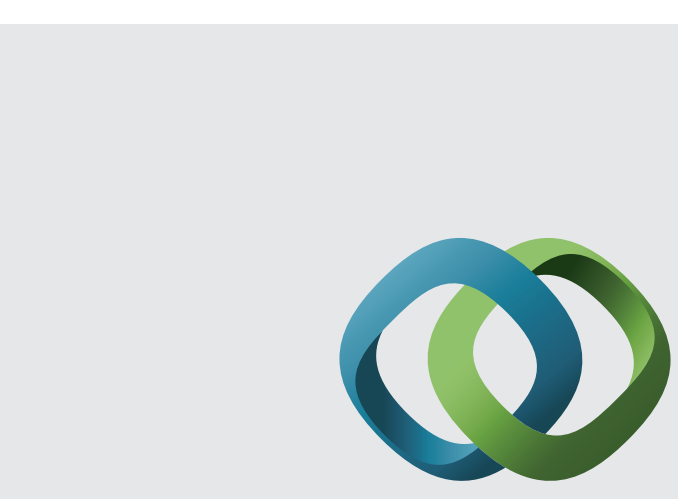

\section{Hindawi}

Submit your manuscripts at

http://www.hindawi.com
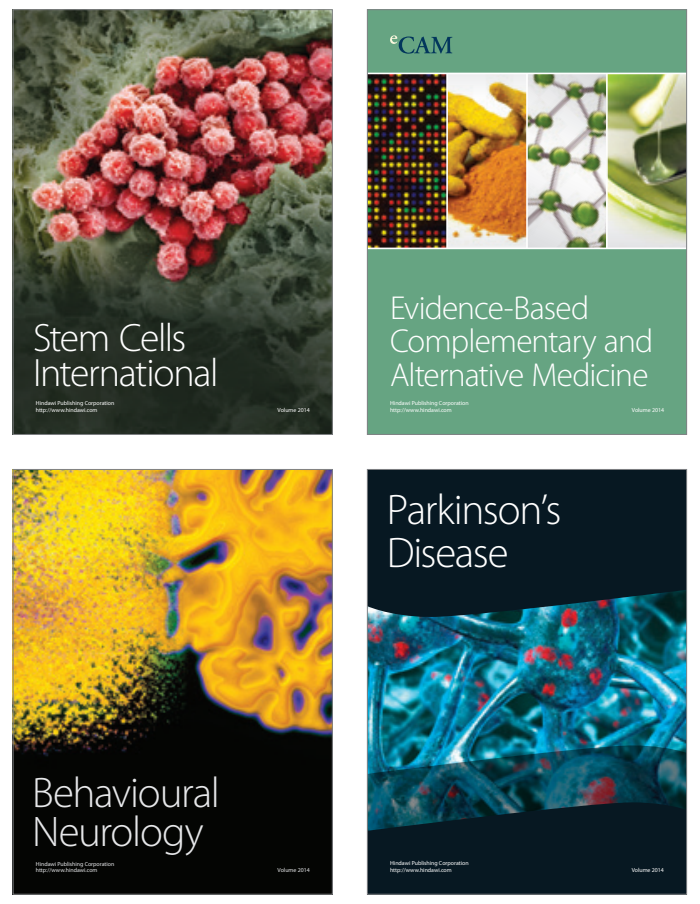
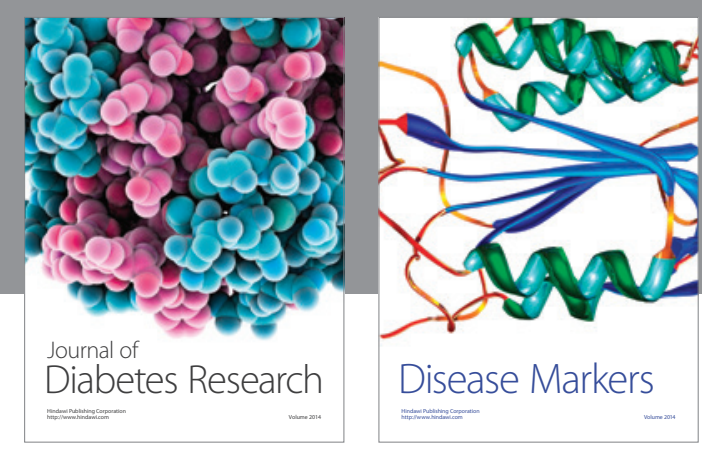

Disease Markers
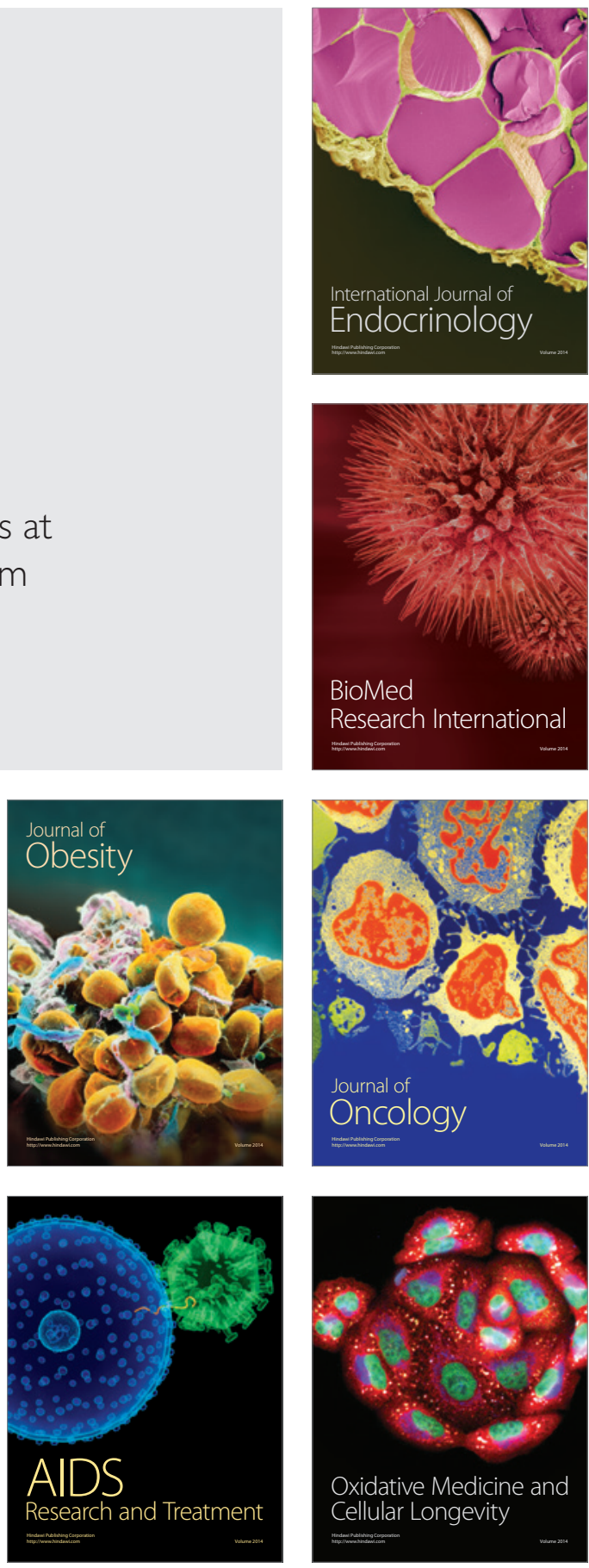